\begin{tabular}{|c|c|c|c|c|c|}
\hline MUNIBE Antropologia-Arkeologia & $n^{\circ} 65$ & $197-213$ & DONOSTIA & 2014 & ISSN 1132-2217 • eISSN 2172-4555 \\
\hline
\end{tabular}

\title{
Las monedas de San Martín de Dulantzi (Alegría-Dulantzi, Álava, País Vasco). Luces y sombras, siglos I - XIV
}

\author{
Coins of San Martín de Dulantzi (Alegría-Dulantzi, Álava, \\ Basque Country). Lights and shadows, centuries I - XIV
}

KEY WORDS: Plain of Álava, monetary circulation, Romanization, Late Antiquity, Middle Ages.

PALABRAS CLAVES: Llanada Alavesa, circulación monetaria, Romanización, Antigüedad Tardía, Edad Media.

GAKO-HITZAK: Arabako lautada, zirkulazio monetarioa, Erromanizazioa, Aintzinate Berantiarra, Erdi Aroa.

\section{Raúl SÁNCHEZ RINCÓN(1), Miguel LOZA URIARTE(2) y Javier NISO LORENZO(2)}

\begin{abstract}
The archaeological intervention of a preventive nature carried out at the site of San Martín de Dulantzi (Alegría-Dulantzi, Álava) brought an unexpected stratigraphic sequence, especially on the each less darks centuries of Late Antiquity. However, despite the important extension of land intervened, about $800 \mathrm{~m}^{2}$, only recovered a total of ten coins. This low density of findings contrasts vividly with the abundant representation of other kinds of material evidence at the site. Although, behind this lack of testimonies coins, hides a complex sequence of occupation developed into a space of use preferably religious and/or funeral, where prevail those historical periods of limited or almost non-existent monetary circulation, including between the $\mathrm{V}$ and $\mathrm{XII}$ centuries.

The coins, without being the most significant archaeological material from a quantitative or qualitative point of view, however, show the apparent contradiction between the numismatic evidence and the archaeological record. And we say apparent because, as we will have opportunity to see over the next lines, absences, in certain cases, can provide information as valuable as those offered by own presences. Within the small cast of pieces found at the site, stand out for their uniqueness exemplary shakes by the Christian kingdoms of the Iberian Peninsula at the end of the 11th century and a rare issue attributed to the Navarrese King Sancho VI the Wise (1150-1194)
\end{abstract}

\section{RESUMEN}

La intervención arqueológica llevada a cabo en las calles Nuestra Señora de Ayala y San Martín, ubicadas en la villa alavesa de Alegría-Dulantzi, ha deparado una inesperada secuencia estratigráfica, especialmente del cada vez menos oscuro periodo tardoantiguo. Las monedas, sin llegar a ser los materiales arqueológicos más significativos desde el punto de vista cuantitativo o cualitativo, arrojan interesantes informaciones relativas a las primeras emisiones monetarias de los reinos cristianos peninsulares a finales del siglo XI.

\section{LABURPENA}

Dulantziko Nuestra Señora de Aiala eta San Martin kaleetan egindako esku-hartze arkeologikoak ezusteko sekuentzia estatigrafikoa ekarri du, gero eta argiago den antzinarotik bereziki. Aztarnategiko material arkeologikoaren artean, txanponak ez dira elementu esanguratsuak, alde kuantitatibo edo kualitatiboei dagokionez behintzat. Baina, penintsulako Kristau erresumatako lehenengo moneta jaulkipenei buruzko argibide baliagarria ematen dute txanponek.

\section{1.- SAN MARTÍN DE DULANTZI. CONTEXTUALI- ZACIÓN ARQUEOLÓGICA}

La villa de Alegría-Dulantzi se encuentra situada en plena Llanada Alavesa, a escasos $15 \mathrm{~km}$ al Este de VitoriaGasteiz. Esta localidad se ha reivindicado desde antiguo como un verdadero referente para la arqueología alavesa. Así, la primera noticia de interés data ya del año 1799 cuando Lorenzo Prestamero presenta una pequeña ara votiva de época romana, provista de la inscripción S SEVER/ TULLONIO/ V S L M (CIL II, 2239), que permitió suponer su relación directa con Tullonium, una de las poblaciones de los várdulos mencionada por Ptolomeo y nuevamente citada en el Itinerario de Antonino (GURRUCHAGA, 1951). A partir de entonces, se inició un camino de hallazgos entre los que destacan el Castro del Castillo de Henayo (LLANOS et al., 1975), donde tradicionalmente se ha situado Tullonium, el yacimiento romano de Angostina (FILLOY y GIL, 2000: 118-119), en el paso de la calzada Ab Asturica Burdigalam y la necrópolis tardoantigua de San Pelayo (relacionada con la excavada en el cercano lugar de Aldaieta) (AZKARATE, 1997; IRIARTE, 1998; AZKARATE, 2005-2006).

(1) Arqueólogo profesional. raul_sanchez_rincon@yahoo.es

(2) Iterbide S.C. iterbide@yahoo.es; janilo3@hotmail.com 


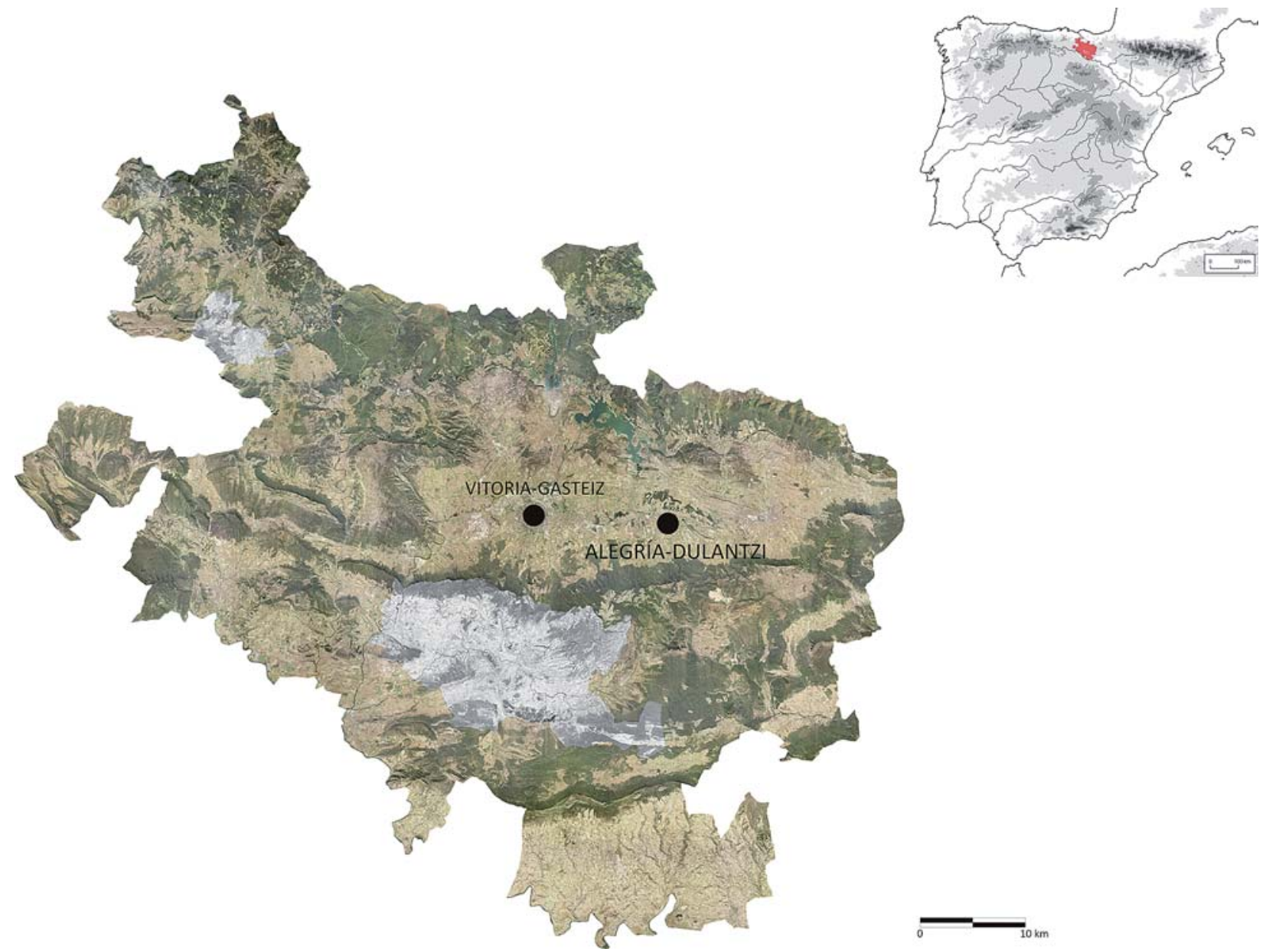

Fig. 1. Localización de la villa de Alegría-Dulantzi en la provincia de Álava. / Location of the town of Alegría-Dulantzi in the province of Álava.

La intervención arqueológica de San Martín de Dulantzi estuvo motivada por la declaración como Zona de Presunción Arqueológica (B.O.P.V., 26/05/1997) de una pequeña área al otro lado del río Alegría, en el actual barrio de Dulantzi, donde diversas referencias situaban la ubicación de la antigua ermita de San Martín, considerada la parroquia primitiva del lugar de Dullanzit (UBIETO, 1976: doc. 180), precedente altomedieval de la propia Alegría.

La decisión del Ayuntamiento de Alegría-Dulantzi de reurbanizar las calles de Nuestra Señora de Ayala y de San Martín, en aquel barrio, propició que la empresa de arqueología Iterbide S.C. Ilevara a cabo la preceptiva intervención, en principio, a nivel de control de obras pero transformada después en excavación en área, debido a la importancia de lo detectado. Estos trabajos fueron llevados a cabo entre los meses de noviembre de 2009 hasta mayo de 2010, estando en la actualidad en pleno proceso de estudio.

En total se intervinieron unos $800 \mathrm{~m}^{2}$, con la dificultad, añadida a la complejidad de la variedad de registros identificados, de tener que compaginar los trabajos arqueológicos con los propios de las obras públicas realizadas.

Pese a dicha complejidad, los resultados fueron altamente satisfactorios, documentándose una amplía secuencia arqueológica dividida en ocho fases históricas, con restos que abarcan desde la prehistoria hasta la actualidad.

FASE 1. Segundo milenio a.C.

FASE 2. Siglo I d.C. - IV d.C.

FASE 3. Siglo V - primera mitad del VI

FASE 4. Segunda mitad del siglo VI - siglo VII

FASE 5. Finales del siglo VII - segunda mitad del siglo IX

\footnotetext{
${ }^{1}$ Tal y como aparece mencionado en "La Reja de San Millán", documento fechado en torno al año 1025, en el que se enumeran una serie de pueblos de la llamada Álava nuclear por tener que pagar tributo en especies al monasterio riojano de San Millán de la Cogolla, y primer testimonio escrito en el que se hace referencia a este núcleo: "Hiraszaeza: Gelhegieta, tres regas. Iscona, tres regas. Troconiz, duas regas. Burgellu et Garonna, duas regas; in alio anno, una rega. Hararihini, una rega. Aialha, duas regas. Larrahara, una rega. Dullanzi, duas regas. Aniu, una rega. Larraza et Arbelgoihen, in duos annos tres regas. Herenizguhin et Habaunza, tres regas. Hamamio, una rega. (Las negritas son nuestras).
} 


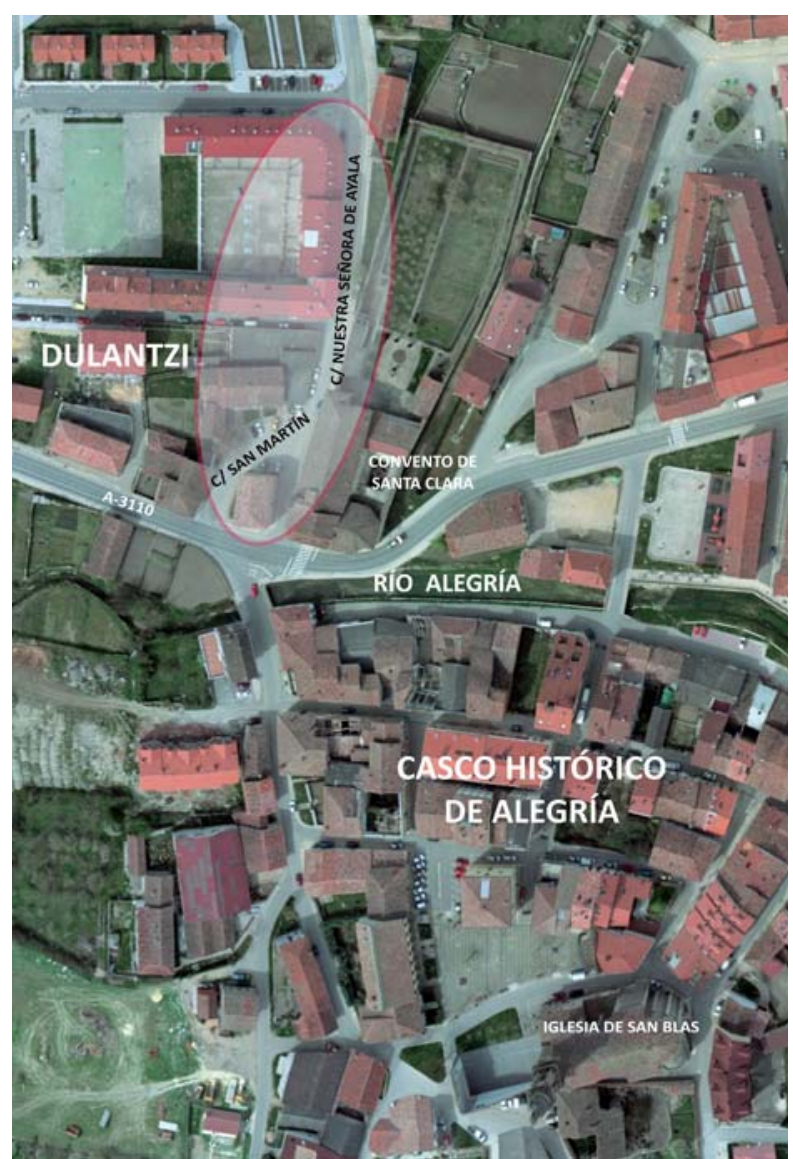

Fig. 2. Vista aérea de la zona intervenida. / Aerial view of the intervened area

FASE 6. Primera mitad del siglo X - siglo XII

FASE 7. Siglo XII - siglo XIV

FASE 8. Siglo XV - siglo XXI

El marco de trabajo de este estudio es muy extenso y afecta a la práctica totalidad de la secuencia recuperada, ya que, si bien no en todas las fases aparecen monedas², la ausencia de ellas, como a continuación se verá, resulta clave para entender algunas de las tesis que se desarrollaran en las próximas líneas. Por ello, antes de entrar en materia, es conveniente realizar un breve repaso de la secuencia histórico-estratigráfica del lugar.

Las primeras evidencias documentadas tienen su origen posiblemente en la Edad del Bronce con varios fondos de cabaña y sus respectivos rellenos de amortización.

Ya en época romana, siglo I-II d.C., se han identificado dos actividades de ocupación. Un primer poblamiento ba- sado en estructuras excavadas (agujeros de poste y rozas) de carácter rupestre y levantes en materiales perecederos y otro posterior con estructuras murarías pétreas en torno a una calle.

En momentos más avanzados, siglo III-IV, se observa una falta de estructuras edilicias de entidad que manifiesten la continuidad en el urbanismo de esta área del yacimiento. Únicamente se detectan algunos testimonios aislados como un pozo, así como un significativo número de depósitos, posiblemente para nivelar la zona, que pueden llegar hasta el siglo IV.

El paso entre el mundo romano y tardoantiguo se caracteriza por una singular ausencia de restos. Tan sólo pudiera existir alguna estructura negativa aislada y, lo que es más importante, los primeros testimonios del uso de este espacio como necrópolis. Se trata de un único enterramiento, fechado por C14 en el siglo $\mathrm{V}$ o la primera mitad del siglo VI, que bien pudiera indicar la presencia de una pequeña necrópolis a partir de la cual se pudo levantar, en la sexta centuria, el gran edificio de culto tardoantiguo.

Este gran edificio religioso estaría asociado, en un primer momento, segunda mitad del siglo VI y siglo VII, con un cementerio de prestigio y, posteriormente, segunda mitad del siglo VII hasta el siglo X, con una necrópolis de carácter más popular posiblemente vinculada con él pero ya sin relación directa. A partir de esta fecha y hasta su total abandono en la segunda mitad del siglo XII, se detectan profundos cambios en la iglesia siendo los más destacados la anulación del baptisterio y la proliferación de silos en el interior del aula y el ábside, que provocan importantes trasformaciones tanto en la necrópolis como en el poblamiento adyacente.

Coincidiendo con el abandono de la iglesia primigenia, a finales del siglo XII, parece edificarse un nuevo templo con su correspondiente necrópolis asociada. Los restos de dicha iglesia no se han hallado en la excavación, pero sí un buen número de las tumbas diseminadas en torno a ella, muchas de ellas cortando a las cimentaciones de la antigua edificación.

Los últimos testimonios de cronología medieval localizados son una serie de suelos que parecen sellar toda la necrópolis anterior y sus respectivos rellenos de abandono que pudieran coincidir con la fundación de la villa de Alegría en el año $1337^{3}$.

\section{2.- ESTUDIO NUMISMÁTICO}

A pesar de la importante extensión de terreno intervenida, en el curso de la excavación arqueológica únicamente

\footnotetext{
${ }^{2}$ A consecuencia del limitado número de piezas halladas durante los trabajos arqueológicos, se ha decidido simplificar la secuencia numismática en tres grandes bloques cronológicos más acordes a la propia realidad del material numismático.

3Para tener una visión más detallada de la secuencia estratigráfica de la intervención de San Martín de Dulantzi se puede consultar J. Niso y M. Loza (2012). Durante los meses de mayo y julio de 2014 se ha podido continuar la investigación arqueológica en el lugar, actuando en una propiedad privada contigua a la zona donde aparecieron los restos del gran edificio de culto. Esta intervención ha permitido constatar la continuidad de la iglesia hacia el Oeste, sin de momento localizar sus límites, así como registrar un interesante conjunto de enterramientos asociados a ella. Además, ha sido posible hallar la cabecera de la antigua iglesia románica de San Martín a los pies del gran templo anterior, pero sin una relación directa con él.
} 


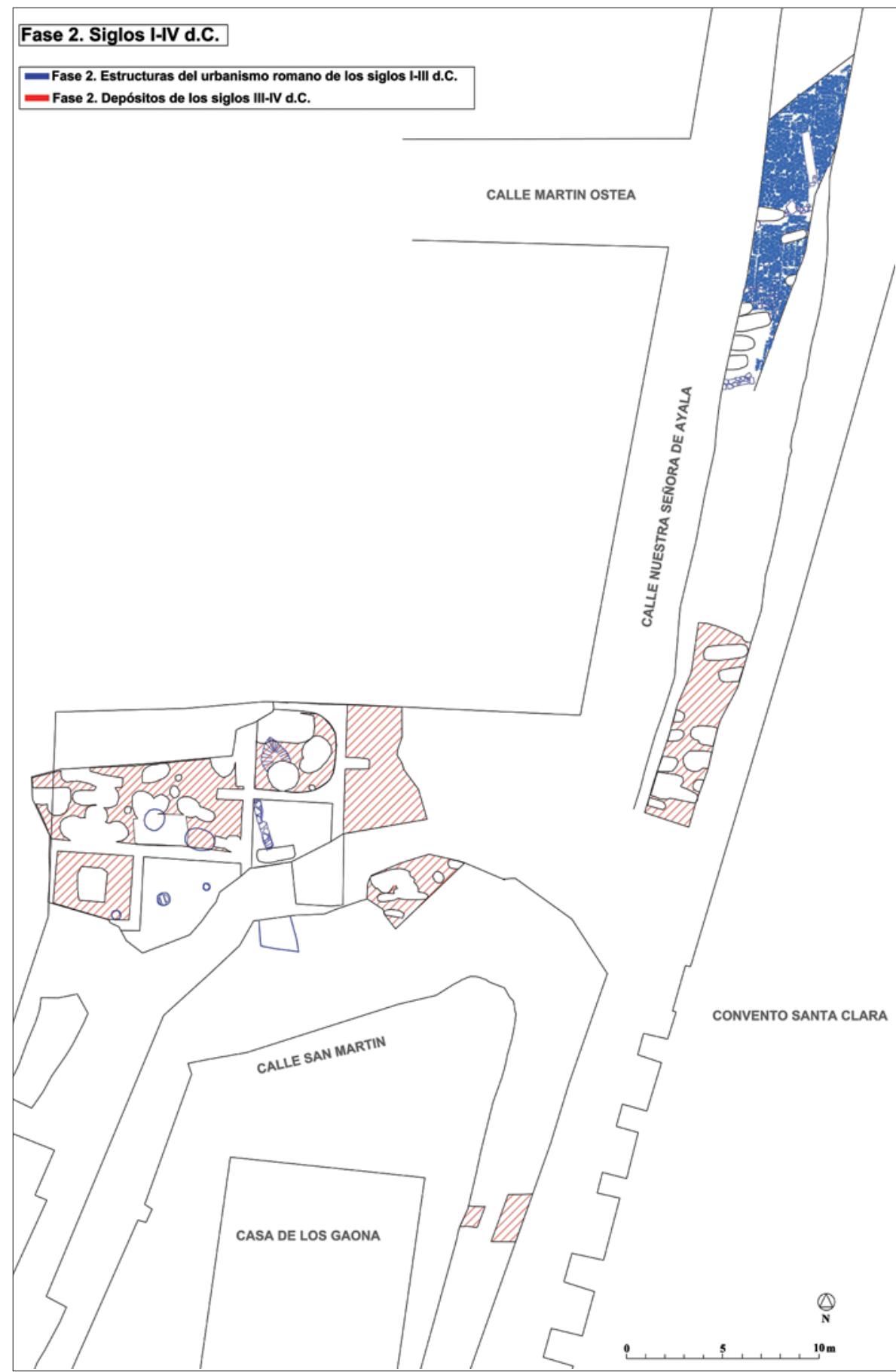

Fig. 3. Planta del yacimiento de San Martín de Dulantzi durante la Fase 2. / Plant of the archaeological site of San Martín de Dulantzi during Phase 2. se recuperaron un total de diez monedas (cuatro piezas romanas, otras cuatro medievales y dos de la Edad Moderna). Esta baja densidad de hallazgos contrasta vivamente con la abundante representación de otro tipo de evidencias materiales en el yacimiento. No obstante, detrás de dicha falta de testimonios monetales se oculta una compleja secuencia de ocupación desarrollada en un espacio de uso preferentemente religioso y/o funerario, donde prevalecen aquellos periodos históricos de limitada o cuasi inexistente circula- ción monetaria, los comprendidos entre los siglos V y XII. Si alguien, por contra, quisiese argüir la existencia de ambientes religiosos y/o funerarios más prolíficos desde el punto de vista numismático, a saber: catedral de Santa María de Vitoria-Gasteiz (AZKARATE et al., 2001: 174-175), iglesia de San Esteban de Oiartzun (IBÁÑEZ et al., 1997) o iglesia de San Salvador de Getaria (GUEREÑU, URTEAGA, 2001); vendría a señalar contextos más tardíos -posteriores al siglo XII-, momento a partir del cual la cadencia de pér- 
dida de moneda de escaso valor aumenta de forma considerable en el registro arqueológico.

\subsection{Los retazos del mundo romano (Siglos I-IV d.c.)}

Sorprende, a primera vista, el reducido número de piezas de época imperial halladas, más si cabe si tenemos en cuenta la significativa aparición de restos y estructuras de cronología romana durante los trabajos de campo (NISO y LOZA, 2012: 36) o que, en el término municipal de Alegría-Dulantzi -en el cercano yacimiento de Angostina-, diferentes investigadores vienen situando una de las mansiones que jalonaban la Iter XXXIV (ab Asturica Burdigalam) a su paso por la provincia de Álava (FILLOY y GIL, 2000: 118-119; NúÑEZ, 2003: 37-38). Nos referimos, en concreto, a la mansio mencionada en el denominado Itinerario de Antonino bajo el nombre de Tullonium, núcleo de población integrado dentro del territorio de los várdulos y que a tenor de las nuevas informaciones disponibles debería identificarse con la aldea de Dulantzi (NISO y LOZA, 2012: 36-37)

Las razones de esa exigua presencia de acuñaciones imperiales en la secuencia histórica del yacimiento, en especial a lo largo de las dos primeras centurias de nuestra era , han de buscarse tanto en las fuertes alteraciones postdeposicionales sufridas por la estratigrafía del periodo (la mayoría de piezas aparecen estratigráficamente descontextualizadas), como en el probable carácter marginal o excéntrico de dicho sector dentro de la trama urbana del asentamiento. Así, la intensa reocupación del lugar en los siglos venideros, fosilizada en el subsuelo a través de centenares de estructuras o unidades estratigráficas negativas (fondos de cabaña, fosas, silos, zanjas para la inserción de servicios modernos,...), va a acabar por desdibujar irremediablemente los vestigios de la etapa romana, dificultando en algunos casos la definición de los mismos (Ibídem: 36). Aún y todo, cuatro fueron las piezas descubiertas: un as altoimperial localizado en los niveles constructivos de un empedrado de finales del siglo I - siglo II d.C. (Moneda 1); un antoniniano de Victorino (Moneda 2) en el relleno de amortización de una de las sepulturas de la necrópolis tardoantigua ( $n^{\circ} 209$ ); un posible aes 3 de la cuarta centuria (Moneda 4), integrando la tierra con la que se colmata un gran fondo de cabaña en el siglo IX; y, por último, un antoniniano de ¿Tétrico I? (Moneda 3), dentro de un heterogéneo estrato formado a lo largo del siglo XX.

En otro orden de ideas, retomando el hilo de la segunda de las dos reflexiones enunciadas, dado que varias estelas funerarias romanas se localizaron en posición secundaria -desplazadas de su posición estratigráfica original-, muchas de ellas reaprovechadas en la edificación de la singular iglesia tardoantigua del siglo VI (Ibídem: 43), no es descabellado aducir que la necrópolis altoimperial se ubicara en sus inmediaciones. Como es de sobra co- nocido, las estrictas leyes romanas establecían que los enterramientos debían realizarse fuera de las ciudades (HAMEROW, 2006: 20), distribuidos por norma general en áreas suburbanas, extra muros, junto a las principales vías de acceso al núcleo urbano (VAQUERIZO, 2002). Ante tales circunstancias, no ha de extrañar la carencia de elementos monetales en el subsuelo.

Por último, cabe destacar el descubrimiento del antedicho antoniniano a nombre del emperador galo Victorino (vid. Supra, Moneda 2), una rareza dentro de la masa de antoninianus empleada en esta zona de la Península durante el último tercio del siglo III. El desgajamiento de las provincias occidentales de las Galias, Britania e Hispania tras la usurpación del general Póstumo, en el llamado Imperio Galo de Póstumo, no fue óbice para que el numerario circulante estuviese dominado por las emisiones itálicas de los emperadores Galieno y Claudio II (CEPEDA, 1997: 273-274). Tampoco hemos de olvidar, abundando en esa línea, el secular origen mediterráneo del aprovisionamiento hispánico. De modo que, no será hasta la puesta en circulación de las series más devaluadas de los Tétricos (vid. Supra, Moneda 3) cuando ambas corrientes de provisión, itálica y continental, adquieran valores similares en nuestro ámbito geográfico (Ibídem: 274).

\subsection{Las sombras (Siglo V- finales del Siglo XI)}

La entrada de suevos, vándalos y alanos en el otoño del año 409 va a desencadenar la lenta pero inexorable desarticulación del aparato político-administrativo del Imperio romano en las antiguas provincias hispanas, afectando, como no podía ser de otra manera, a todos los órdenes de la vida cotidiana de sus habitantes. Sin embargo, quizá el colapso de las estructuras del estado imperial pudo manifestarse en primer lugar en las esferas económicas, en atención a una serie de indicios y certidumbres. El prematuro cese de provisión de moneda fraccionaria de bronce, a finales del siglo IV o inicios del siglo V (CEPEDA, 2000a: 173) o la interrupción del suministro de las emisiones áureas, poco después de la irrupción de los contingentes bárbaros (Ibídem: 171), parecen anunciar la temprana quiebra de relaciones con la corte imperial. No es ocioso recordar los recientes episodios de usurpaciones vividas en suelo hispano por parte de los usurpadores Constantino III o Máximo, durante los años 408-411 (CEPEDA, 2000b: 44-47), que, junto al establecimiento de poblaciones foráneas, conforman el caldo de cultivo ideal de tensión social que explicaría buena parte de las ocultaciones datadas en los albores de la quinta centuria (CEPEDA, 2000a: 173).

La ruptura de amarras con la pars Occidentis marca el punto de partida de un largo tránsito de marginalidad monetaria en tierras alavesas y, en general, en todos los territorios vascos de la Vasconia altomedieval, que se pro-

${ }^{4}$ Años de una pujante economía de mercado desarrollada en los enclaves de mayor entidad, a la sazón, emplazados en redor del trazado de los distintos ejes viarios de comunicación que surcan el territorio alavés (CEPEDA, 1990: 163-164; FILLOY y GIL, 2000: 42-47). 
longará hasta las postrimerías del siglo XI, momento en el cual darán comienzo las labras de los reinos cristianos peninsulares de Aragón-Pamplona (IBÁÑEZ, 2001) y de Castilla-León (ROMA, 2010: 167-171). Unos siglos caracterizados por un páramo de hallazgos numismáticos trufados aquí y allá por pequeños puntos de luz que iluminan tenuemente nuestro conocimiento sobre el uso de la moneda en un periodo cada vez menos oscuro (Cfr. QUIRÓS, 2011). El tremissis hispalense de Recesvinto (653672) de la Peña de Orduña (OCHARAN, 1983); el dirham omeya oriental de la catedral de Santa María de VitoriaGasteiz (AZKARATE, 2010: 137); los cuatro dirhames del Califato, tres de ellos fracciones de dirham, de Andagoste y Caicedo-Sopeña (OCHARAN, 2009) o los dos dineros aquitanos del conde Guillermo Sancho (977-996) de la ermita de Santa Elena de Irun (BARANDIARAN, 1975), son los únicos ejemplares que a día de hoy podemos citar. Más adelante retomaremos esta cuestión.

Volviendo la mirada a realidades más apegadas al suelo, la extraordinaria secuencia de ocupación de época tardoantigua (segunda mitad del siglo VI - siglo VII) del yacimiento de San Martín de Dulantzi ha ofrecido un variadísimo elenco de indicadores de poder y prestigio absolutamente novedosos en nuestras coordenadas geográficas. Además de la habitual panoplia guerrera de filiación franca, ampliamente documentada en la célebre necrópolis de Aldaieta (Nanclares de Gamboa, Álava) o en otras más modestas como las de San Pelayo (AlegríaDulantzi, Álava), Finaga (Basauri, Bizkaia) o Santimamiñe (Kortezubi, Bizkaia) (QUIRÓS, 2009: 389), han aparecido edificaciones y objetos tan excepcionales como: un centro de culto de planta basilical de inusuales dimensiones, ajeno al ambiente técnico de la comunidad5; dos cucharillas de plata, en una de las cuales grabaron sobre la ca- zoleta una curiosa escena mitológica o tres anillos, uno de ellos de oro macizo engarzado con una piedra azul de pasta vítrea 6 (NISO y LOZA, 2012: 39-47; QUIRÓS, LOZA y NISO, 2013: 219-223). En contra de la imagen transmitida por los autores tardoantiguos, sea Isidoro de Sevilla, Venancio Fortunato, Gregorio de Tours o Julián de Toledo, siempre plagada de estereotipos negativos en relación a los vascones, las fuentes arqueológicas muestran unas estructuras sociales mucho más complejas, no tan arcaicas, que las reflejadas por los textos escritos y, por ende, por gran parte de la historiografía tradicional (POZO, 2011). Antes bien, aunque algunos de los materiales recuperados pudieron haber sido confeccionados en el propio asentamiento o enclaves cercanos (AZKARATE et al., 2011: 81; AZKARATE y GARCÍA CAMINO, 2012: 341-342), la identificación de diversos marcadores arqueológicos que transcienden inequívocamente el ámbito local (élites inhumadas con ricos ajuares personales y/o depósitos funerarios en torno a una gran iglesia), sugieren la existencia de amplias redes comerciales por las que circularían indistintamente ideas, objetos o personas ${ }^{7}$. Un ir y venir de mercancías y mano de obra cualificada donde la moneda, en este caso de oro ${ }^{8}$, debió desempeñar un papel menor o residual como medio de cambio en las transacciones económicas en vista a su escasa incidencia en el registro arqueológico de este sector del norte peninsular (CANTO et al., 2011: 180-182; RETAMERO, 2011: 202-206).

La conquista islámica no se deja sentir en el subsuelo del yacimiento ${ }^{9}$ y menos aún en el registro numismático. Si bien, dicha circunstancia no debe sorprendernos si atendemos al reducido número de hallazgos documentados en los territorios circundantes (CANTO, 2001: 77-81; ROMA, 2010: 102; CANTO et al., 2011: 177-186). Por fortuna, en los últimos años se han ido sucediendo una serie de des-

\footnotetext{
${ }^{5}$ Mientras que en la edificación del templo se recurrió al uso de técnicas constructivas más complejas (íntegramente en piedra); en paralelo, las viviendas del lugar, modestas cabañas, se levantaron en materiales efímeros (madera y barro). El repertorio cerámico, por su parte, se reduce a sencillos recipientes de formas cerradas y tosca factura.

${ }^{6}$ En opinión de sus descubridores, tales piezas, hablamos de las cucharillas metálicas y, acaso, de la sortija de oro con cabujón, han de vincularse indudablemente con elementos litúrgicos cristianos asociados a individuos de privilegiada posición social (Ibídem: 46-47). Dentro de dicha línea argumental resulta oportuno traer a la memoria el carácter beneficioso y/o profiláctico otorgado en la Edad Media a las gemas, se trate de piedras preciosas o sucedáneos. "It should also be noted that the use of substitutes for real gems need not imply a lack of wealth, as even objects owned by the great medieval monarchs were sometimes set thus; Standley reports that found among royal jewels in France and England were coloured glass stones set as gems. In medieval Europe precious stones were believed to have contained within them inherent beneficial properties which could be absorbed if worn close to the body. Medieval lapidaries, such as the famous tome authored by Marbode, Archbishop of Rennes, were 'textbooks' which recorded the medicinal and prophylactic qualities possessed by the various gems." (KELLEHER, 2012: 192).

${ }^{7}$ La vieja calzada romana ab Asturica Burdigalam que, años atrás había servido de puerta de entrada a ejércitos de muy distinta condición, hubo de ejercer de correa de transmisión entre ambos mundos, el vascón y el continental. Como se ha atestiguado recientemente en el yacimiento de Mariturri (Vitoria-Gasteiz, Álava), la vía no sólo se seguía utilizando durante los siglos VI y VII sino que cuando así se hacía necesario se velaba por su correcta conservación. En una de las refacciones que afectan al firme de la calzada a su paso por el yacimiento, pudo recuperarse "sobre el pavimento una punta de lanza, una framea, cuyas características morfológicas permiten relacionarla con las halladas en conocidas necrópolis tardoantiguas y a falta del estudio definitivo, situar una reparación de la vía efectuada, como mínimo, en la segunda mitad del siglo VI d.C." (SÁENZ DE URTURI y NÚÑ̃EZ, 2004: 196).

8 "Los visigodos, también los francos y otras tribus bárbaras (DEPEYROT, 1998), que conocían y utilizaban la moneda del Imperio romano, basaron su sistema monetario en el oro. A pesar que en sus momentos iniciales adoptaron el solidus, pronto el tremissis -un tercio del solidus- se consolidó como única moneda. Algunos investigadores han defendido que la producción monetaria del Reino visigodo fue escasa y que su uso fue restringido, pues sólo se utilizó para realizar pagos militares y para adquirir objetos de lujo. También se le ha otorgado una naturaleza preferentemente fiscal, con el objetivo de recaudar los impuestos con eficacia y agilidad. En cualquier caso, se puede confirmar que los hallazgos de monedas visigodas son extremadamente escasos y, por lo tanto, poco significativos para establecer una valoración sobre la trascendencia de los hábitos monetarios durante este período." (MAROT, 2001: 69-70). Palabras referidas a la Navarra de época visigoda que bien podrían extrapolarse al resto de territorios vascones. (Las cursivas son nuestras).
} 


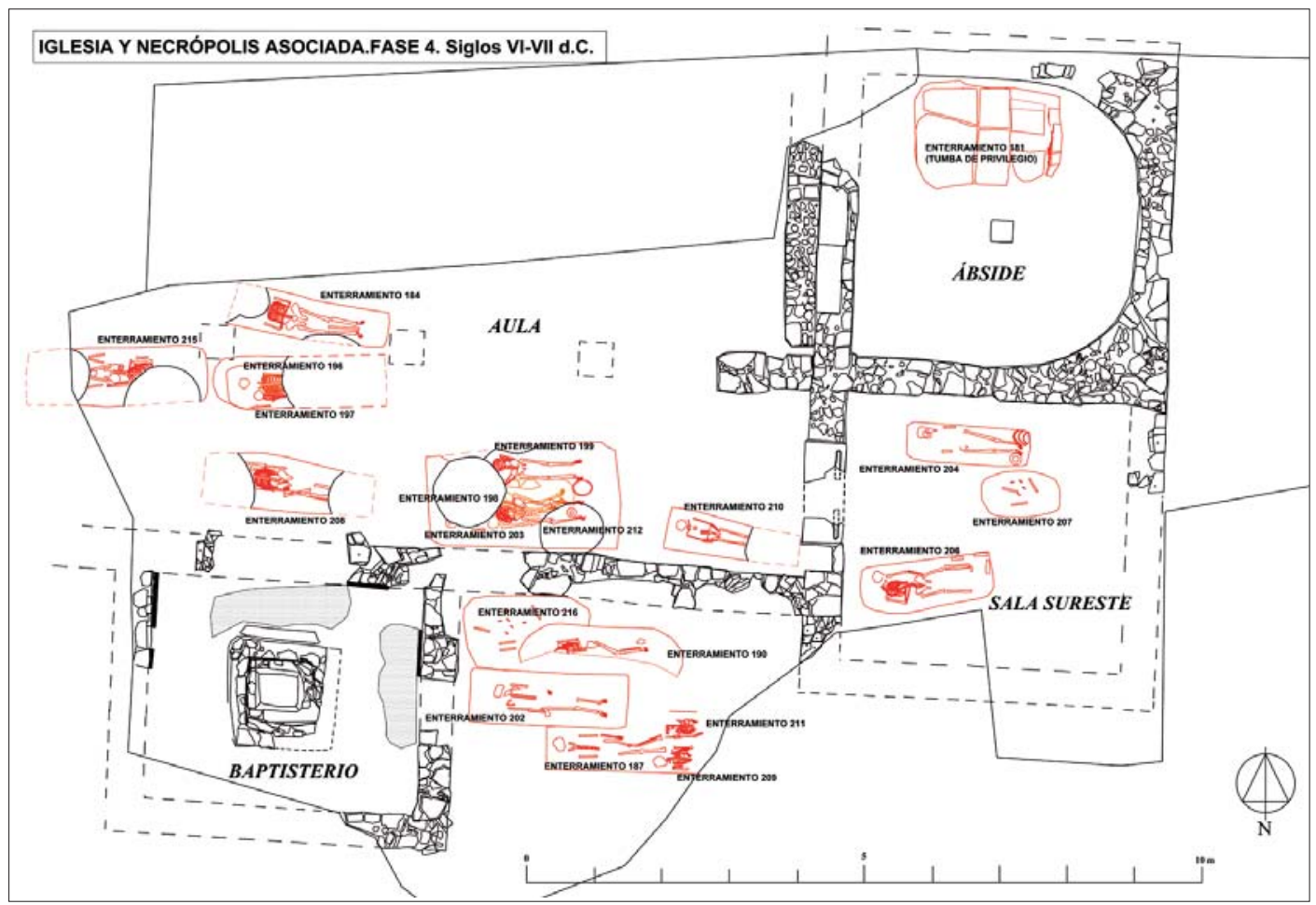

Fig. 4. Planta del edificio religioso tardoantiguo y enterramientos asociados. / Plant of Late Antiquity religious building and associated burials.

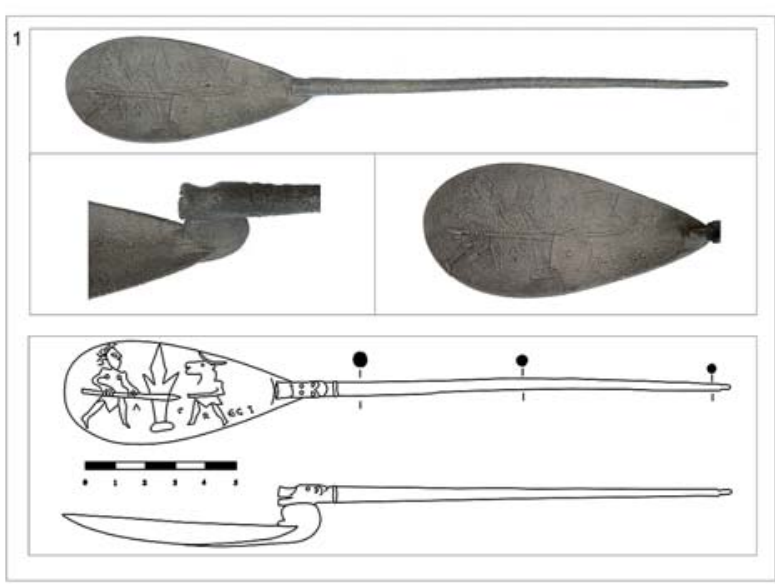

$$
2
$$

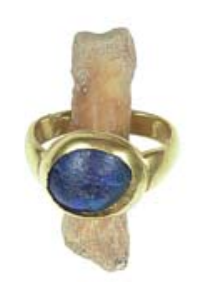

Fig. 5-1. Algunos de los principales objetos hallados en el interior de las sepulturas tardoantiguas. 1) Cuchara de plata decorada; 2) Anillo de oro con cabujón de pasta vítrea; 3) Vaso de vidrio. ( Some of the main objects found inside the Late Antiquity graves. 1) Decorated silver spoon; 2) Gold ring with cabochon of vitreous paste; 3) Glass tumbler.
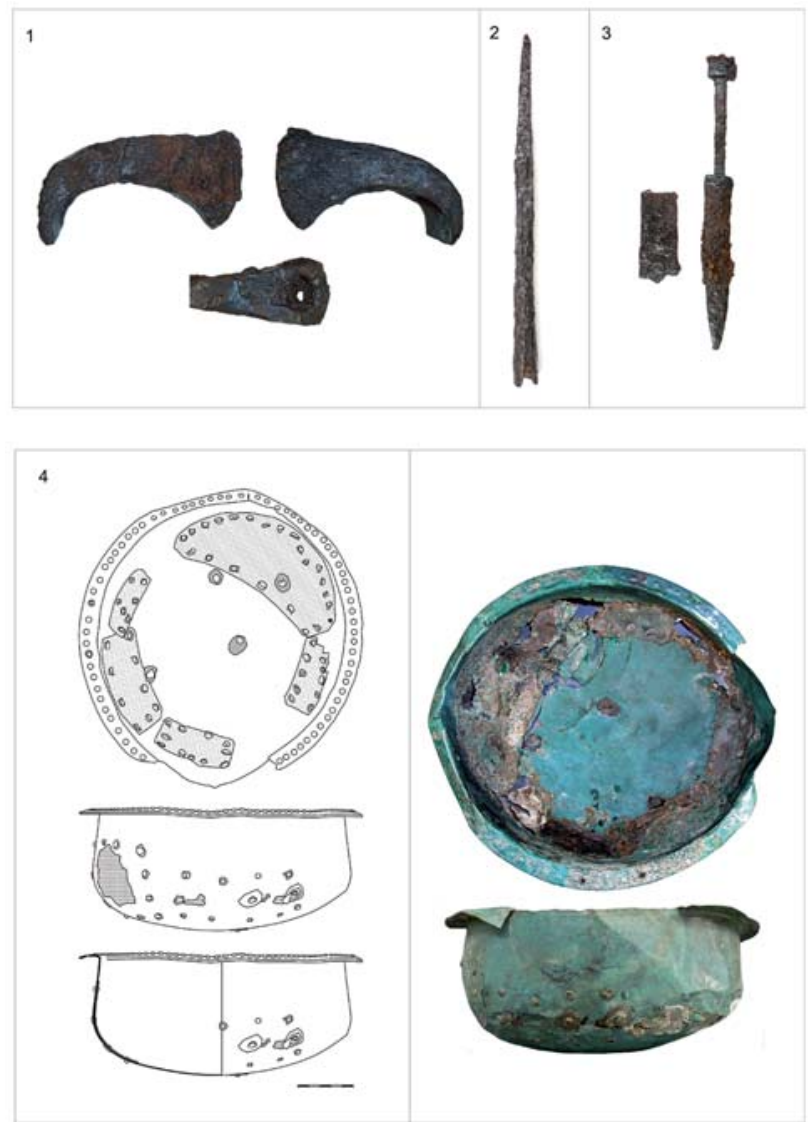

Fig. 5-2. Otros materiales de interés recuperados en la necrópolis.1) Hacha de hierro; 2) Punta de lanza; 3) Cuchillo; 4) Cuenco de bronce. / Other materials of interest recovered in the necropolis. 1) Iron axe; 2) Spearhead; 3) Knife; 4) Bronze bowl. 
cubrimientos en el Territorio Histórico de Álava que vienen a paliar el obstinado silencio que definía, hasta comienzos de la década pasada, el registro arqueológico de la provincia en lo referente a sus relaciones con al-Andalus. Al respecto citaremos, por un lado, el dirham, del periodo de la Conquista, del califa Sulayman (714-718) acuñado en Ardašîr Jurra (Firuzabad, provincia de Fars, Irán) en el año 98 de la Hégira, es decir, el 716-717 de la era cristiana, perdido en un relleno de nivelación de la segunda mitad del siglo X, en la catedral de Santa María de Vitoria-Gasteiz (AZKARATE y SOLAUN, 2009: 425; SAN VICENTE, 2013: 365366); y por otro, los cuatro dirhames andalusíes localizados en el occidente alavés: tres dirhames de Hisam II (9761013), sólo uno de ellos en estado completo (sin fragmentar), en Jokano (Kuartango), en la zona de Andagoste; y una fracción de Al-Hakam II (961-976) en Caicedo-Sopeña (Ribera Alta) (OCHARAN, 2009: 249). Se ha argumentado, con acierto, que las monedas se encontraron en prados yermos, dispersos entre sí y alejados de cualquier centro de población anteriormente habitado, en una época en la que los musulmanes hace tiempo que han cesado de asolar las tierras alavesas (Ibídem: 249-251). En Inglaterra, donde son habituales los hallazgos en pleno campo, en razón de una legislación más permisiva con el uso de los detectores de metales, son varias las hipótesis interpretativas que barajan los investigadores en relación al descubrimiento de grupos de monedas aisladas. Así, por un lado, ciertos investigadores vienen planteando si, acaso, algunos de esos hallazgos, no deberían ser interpretados como depósitos intencionados (KELLEHER, 2012: 197), "since there is some evidence for offerings of food and ampullae of holy water being placed to ensure a fruitful harvest" (Ibídem: 196). Otros (la mayoría) tienden, en cambio, a vincular dichos hallazgos con lo que la literatura científica anglosajona ha venido a denominar 'productive' site (ULMSCHNEIDER y PESTELL, 2003). Esto es, los lugares donde se ubicaban antiguos mercados, ferias y/o asentamientos que participaban en el comercio ( Ibídem: 2), ya fueran de iniciativa secular (LEAHY, 2003) o eclesiástica (NEWMAN, 2003; PESTELL, 2003). En el caso que nos ocupa, aunque es grande la tentación de poner en relación dichos hallazgos bien con rituales de carácter propiciatorio celebrados en los campos para asegurarse la mejor de las cosechas posibles ${ }^{10}$, bien con centros productivos donde se estuvieran elaborando las rejas de hierro que el monasterio de San Millán exigía al valle de Kuartango ("In Quartango, duodecim regas") 11, debemos mantener una postura cauta respecto a la interpretación de los mismos a la espera de que futuras investigaciones en el citado paraje puedan arrojar algo de luz sobre tan incierto asunto.

Nos encontramos, en definitiva, ante comunidades rurales con un restringido acceso al medio circulante que recurrirían al trueque o la retribución en especies para llevar a cabo sus intercambios y pagos cotidianos ${ }^{12}$, como así parece desprenderse del análisis conjunto de las fuentes arqueológicas y documentales (CANTO et al., 2011). En efecto, mientras durante los siglos X-XII las estancias principales -aula central y ábside- de la iglesia se convierten en almacén improvisado donde acopiar, mediante la apertura de decenas de silos de almacenaje, las rentas extraídas a los campesinos (NISO y LOZA 2012: 52-53); en pleno siglo XI, la aldea de Dullanzi aparece tributando, junto a otras pequeñas localidades del territorio, dos rejas de hierro al monasterio de San Millán de la Cogolla.

\footnotetext{
${ }^{9}$ De hecho, no se observan ni niveles de abandono, ni de destrucción, ni siquiera de incendio. Tal vez, las únicas novedades reseñables provengan del mundo de la muerte. A partir de finales de la séptima centuria, o ya en el curso de la siguiente, los habitantes del lugar dejan de buscar el amparo inmediato del edificio religioso para sus difuntos, abandonándose de manera definitiva las costumbres funerarias dominantes hasta fechas recientes, l'inhumation habillée. Desde ese instante, las variantes sepulcrales se diversifican (sepulturas de fosa simple y de muretes), conviviendo ambos tipos en un mismo ámbito y en determinados momentos cronológicos (NISO y LOZA, 2012: 51).

${ }^{10}$ No debemos olvidar cómo, a partir del año mil, al calor de la manifiesta mejora de las condiciones climáticas vividas en la Europa occidental, hasta por lo menos el año 1200, el llamado Período Cálido Medieval (Le Roy Ladurie, 1971; Lamb, 1982; Fagan, 2008), se experimentó un notable crecimiento demográfico que provocó, por ejemplo, la roturación de suelos menos aptos para la práctica agrícola (Díaz de Durana, 1986: 77-89).

En Mavilla, Estavillo (Armiñón, Álava), la aparición en el fondo de un silo de almacenaje de grano de un esqueleto de cría de perdiz roja (Alectoris rufa), dentro de una orza dispuesta boca abajo, ha sido puesto en relación, con reservas, por sus excavadores "con el complejo mundo de las creencias y supersticiones de una sociedad de escaso desarrollo tecnológico y marcado carácter rural, en la que la supervivencia dependía de unas cosechas irregulares, pero casi siempre escasas, y de unos sistemas de conservación rudimentarios pero ingeniosos y eficaces, que debían garantizar la continuidad del ciclo productivo." (FERNÁNDEZ BORDEGARAI y AJAMIL, 2011: 256). Quizás, también, desde dicha perspectiva haya de ser entendida, como special deposits (HAMEROW, 2006), la presencia de animales completos o semi-completos en los rellenos de amortización de los silos medievales (FERNÁNDEZ BORDEGARAI y AJAMIL, 2011: 256; SÁNCHEZ RINCÓN, 2011: 227, nota 15). "While foundation deposits are rare, this survey suggests that termination deposits, particularly those associated with SFBs -sunken-featured building-, are comparatively widespread in Anglo-Saxon settlements. Their precise meaning(s) are unlikely ever to be reached through archaeological evidence alone although, if some SFBs were indeed used for grain storage, the concentration of special deposits in these structures could point to a fertility ideology in which such sacrifices were a means of offering thanks to chthonic powers and calling on them to protect the stored grain and ensure future fertility." (HAMEROW, 2006: 28). (Las cursivas son nuestras).

${ }_{11}$ No es ocioso recordar que las aldeas del Álava nuclear, hacia el año 1025, están contribuyendo al cenobio riojano con cantidades variables de rejas de hierro. Un bien de suma importancia para una economía de base agraria como es la medieval, el cual, por cierto, parece tener una demanda comercial exterior si nos atenemos a la documentación escrita de la época. De tiempos de Sancho V Ramírez (1076-1094) se conserva una tarifa de peaje que gravaba las mercancías que entraban en Pamplona camino de Jaca, entre los diferentes productos gravados se alude, por ejemplo, el hierro probablemente de origen alavés (GAUTIER-DALCHE, 1982: 238).

${ }^{12}$ En Álava, ya en la décima centuria, en compraventas de cierta entidad, imposiciones de penas pecuniarias o pagos de mayor calado, en cambio, son frecuentes, en la documentación, las menciones a unidades de cuenta como libras cocto auri o libras de auri cocto (UBIETO, 1976: 41 y 123); libras aureas (PÉREZ SOLER, 1970: 36); libras auri (UBIETO, 1976: 44, 59, 68 y 83), auri libra o auri libras (PÉREZ SOLER, 1970: 38 y 66); talenta auri (UBIETO, 1976: 50 y 60); solidos (PÉREZ SOLER, 1970: 31, 59, 60, 62 y 66; UBIETO, 1976: 32, 68, 79 y 123) o solidis (UBIETO, 1976: 71 y 83); solidos argenteos (PÉREZ SOLER, 1970: 38); y, solidos de argenzos (Ibídem: 60 y 66).
} 


\subsection{Las luces (finales del Siglo XI - Siglo XIII)}

Como ya se ha señalado, en el último tercio del siglo XI la conjunción de factores de diversa índole (quiebra del Califato de Córdoba; toma de importantes plazas fuertes, Pamplona en el 1076 y Toledo en 1085; concesión de fueros a villas como Jaca en torno a 1077; apertura del Camino Francés; etcétera) van a desencadenar el comienzo de las acuñaciones de los reinos cristianos peninsulares, en un momento inicial en Aragón-Pamplona y unos años más tarde en los reinos de Castilla y León. Si obviamos el controvertido mancuso de Sancho V Ramírez de Aragón y Pamplona (1063-1094) (CRUSAFONT, 1992 49; IBÁÑEZ, 2001: 87) o la breve serie de dirhames de Alfonso VI de Castilla y León (1073-1109) con leyendas en escritura cúfica (ÁLVAREZ BURGOS, 1998: 13; ROMA, 2000: 19), las primeras emisiones aragonesas-pamplonesas y castellanas-leonesas se caracterizan por la enorme cantidad de numerario de vellón fabricado ${ }^{13}$, la profusa variedad de cuños empleados o el sinfín de marcas de emisión identificadas (IBÁÑEZ, 2001: 89; ROMA, 2010: 169-170).

Aquella abundante masa de moneda de vellón introducida en los mercados, no obstante, apenas ha dejado rastro entre los hallazgos de circulación. Al punto que, en la actualidad, únicamente se conocen dos meajas de Alfonso $\mathrm{VI}$ de la serie aros y estrellas procedentes de las intervenciones realizadas en el Túnel de San Adrián (GARCÍA RETES, 1987: 396) y en San Martín de Dulantzi (vid. Infra, Moneda 6) o tres dineros jaqueses de Sancho $\checkmark$ Ramírez presentes en el referido Túnel de San Adrián (Ibídem: 410), en Armentia (AZKARATE, 2005: 205) y, de nuevo en San Martín de Dulantzi (vid. Infra, Moneda 5). Recientemente, empero, el Grupo de Investigación en Patrimonio y Paisajes Culturales (GIPYPAC) ha sacado a la luz en el despoblado de Zaballa un interesante tesorillo compuesto por 29 piezas de Sancho V Ramírez y una de Pedro I (SAN VICENTE, 2012: 345-350), lo cual podría estar revelando que buena parte del circulante debió ser tesaurizado. Es sintomático que tras la llegada de las antedichas especies monetarias va a abrirse, no sólo en San Martín sino también en el registro arqueológico provincial, un elocuente hiato en la renovación del circuito monetario que perdurará hasta bien entrada la segunda mitad del siglo XII ${ }^{14}$ (Moneda $7^{15}$ ). Años donde la notoria ausencia de plata en los reinos peninsulares (ROMA, 2010: 93-116) inducirá a los sectores más acaudalados de la sociedad a atesorar sus ahorros en espera de tiempos mejores.

El reducido elenco del numerario medieval relata, a grandes rasgos, los azarosos acontecimientos que sacuden a nuestro territorio a lo largo de los convulsos si- glos XI y XII. Durante dichas centurias estas tierras van a convertirse en un juguete roto en manos de sus poderosos vecinos, castellanos y pamploneses, hasta su incorporación definitiva al reino de Castilla a inicios del año de 1200 (SÁNCHEZ RINCÓN, 2008: 7-9). Un intermitente viaje de ida y vuelta, de mudas de soberanía, de asesinatos, de intrigas palaciegas,... con varias paradas en su camino: entre los años 1024 y 1076 sujeta a la soberanía pamplonesa; desde 1076 a 1134 integrada en la corona castellana; y, a partir de 1134 hasta el 1200 dentro del reino de Pamplona-Navarra (en 1162 se sustituye el corónimo de Pamplona por el de Navarra). Álava pasaba, entonces, a constituirse en un espacio de frontera permeable a las influencias provenientes de ambos mundos y donde no sería extraña la convivencia de valores ajenos al poder reinante (ROMA, 2010: 106). El dinero jaqués de Sancho V Ramírez sería un buen ejemplo de lo que venimos reseñando.

El bloque de la moneda medieval se cierra con el dinero de Fernando IV (1295-1312), monarca de Castilla y León, batido, tal vez, durante su minoridad por alguno de los regentes en su nombre (Moneda 8). A diferencia del resto de piezas, recuperadas en los rellenos de amortización de diferentes enterramientos ( $n^{\circ}$ 8, 30 y 174; Monedas 5, 6 y 7, respectivamente), el ejemplar de Fernando IV se halló en el nivel de abandono de uno de los empedrados bajomedievales. Aunque la presencia de numismas en el interior de las tumbas tiende a explicarse, por regla general, como ofrendas vinculadas al óbolo de Caronte (IBÁÑEZ, 2007: 288-290) o con el surgimiento y desarrollo del concepto del Purgatorio (GARCÍA CAMINO, 2002: 239-240), creemos que son reduccionismos interpretativos a matizar (SÁNCHEZ y ROMA, 2014). En realidad, salvo en contadas ocasiones, se analiza si la cronología del finado y la de la moneda son coincidentes, es decir, si el elemento monetal está en fase o desplazado de su posición estratigráfica original o si los numismas se colocaron junto a los difuntos. En la necrópolis de San Martín, de las más de 200 sepulturas exhumadas, tan sólo en cuatro de ellas aparecieron monedas (una de época romana y las restantes medievales), pero en ningún caso asociadas al cadáver. Si bien es cierto que todas ellas aparecieron en la tierra arrojada sobre el cuerpo, en el relleno inferior de la fosa. Es decir, dichas piezas bien pudieron ser tiradas intencionadamente durante el sepelio, sin embargo no fueron depositadas ex professo en algún punto concreto del cuerpo del difunto. En toda Inglaterra (el País de Gales incluido), por ejemplo, han reconocido inequívocamente el aludido ritual funerario en un total de diecinueve inhumaciones (KELLEHER, 2012: 197-198).

\footnotetext{
${ }^{13} \mathrm{~A}$. Roma Valdés, para las dos primeras series castellano-leonesas, estima un volumen de producción superior a los 7,5 millones de dineros por tipo (ROMA, 2010: 170).

${ }^{14}$ La excepción que confirma la regla viene a ser el dinero de Alfonso I de Aragón y Pamplona (1104-1134) recuperado en el Túnel de San Adrián (GARCÍA RETES, 1987: 410-411)

15Durante la campaña del 2014 se ha recuperado junto al enterramiento 244 un ejemplar de similares características al presentado en este trabajo.

Para ser exactos, la moneda se encontró sobre la espalda de un individuo inhumado decúbito prono.
} 


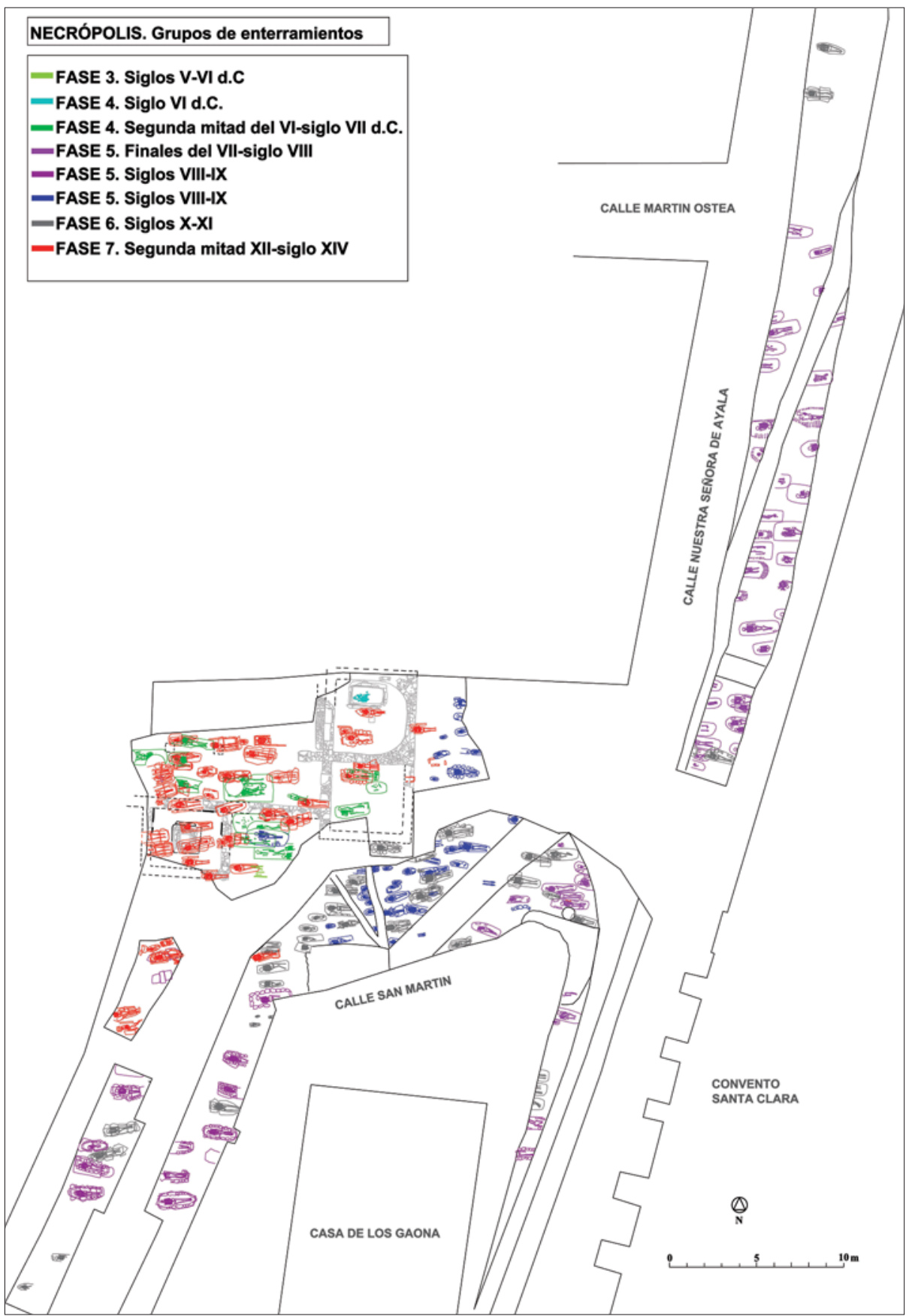

Fig. 6. Planta del yacimiento con las diferentes fases de la necrópolis. / Plant site with the different phases of the necropolis.
La concesión de la carta puebla a la villa de Alegría en el año 1337, marcó el lento, pero inexorable abandono de la pequeña aldea de Dullanzi en favor del enclave recién fundado; permaneciendo, como testigo mudo de excepción, hasta su completo desmantelamiento en el siglo XIX, la ermita de San Martín. Aún y todo, los habitantes del lugar continuarán extraviando alguna que otra moneda en aquel olvidado paraje (Monedas 9 y 10), desconocedores del rico legado oculto bajo sus pies. Y es que, como bien recuerda la copla, cómo, a nuestro parecer, cualquier tiempo pasado, fue mejor.

\section{3.- CONCLUSIONES}

La excavación arqueológica de carácter preventivo realizada en el yacimiento de San Martín de Dulantzi es un buen ejemplo de cómo las ausencias, en ciertas ocasiones, pueden llegar a aportar informaciones tan valiosas como las ofrecidas por las propias presencias. Así, sorprende a primera vista que en una intervención de cierta envergadura como la llevada a cabo en San Martín, afectando una extensión de unos $800 \mathrm{~m}^{2}$, tan sólo se recuperaran un total de diez monedas. No obstante, tras este reducido número de elementos monetales se oculta un es- 


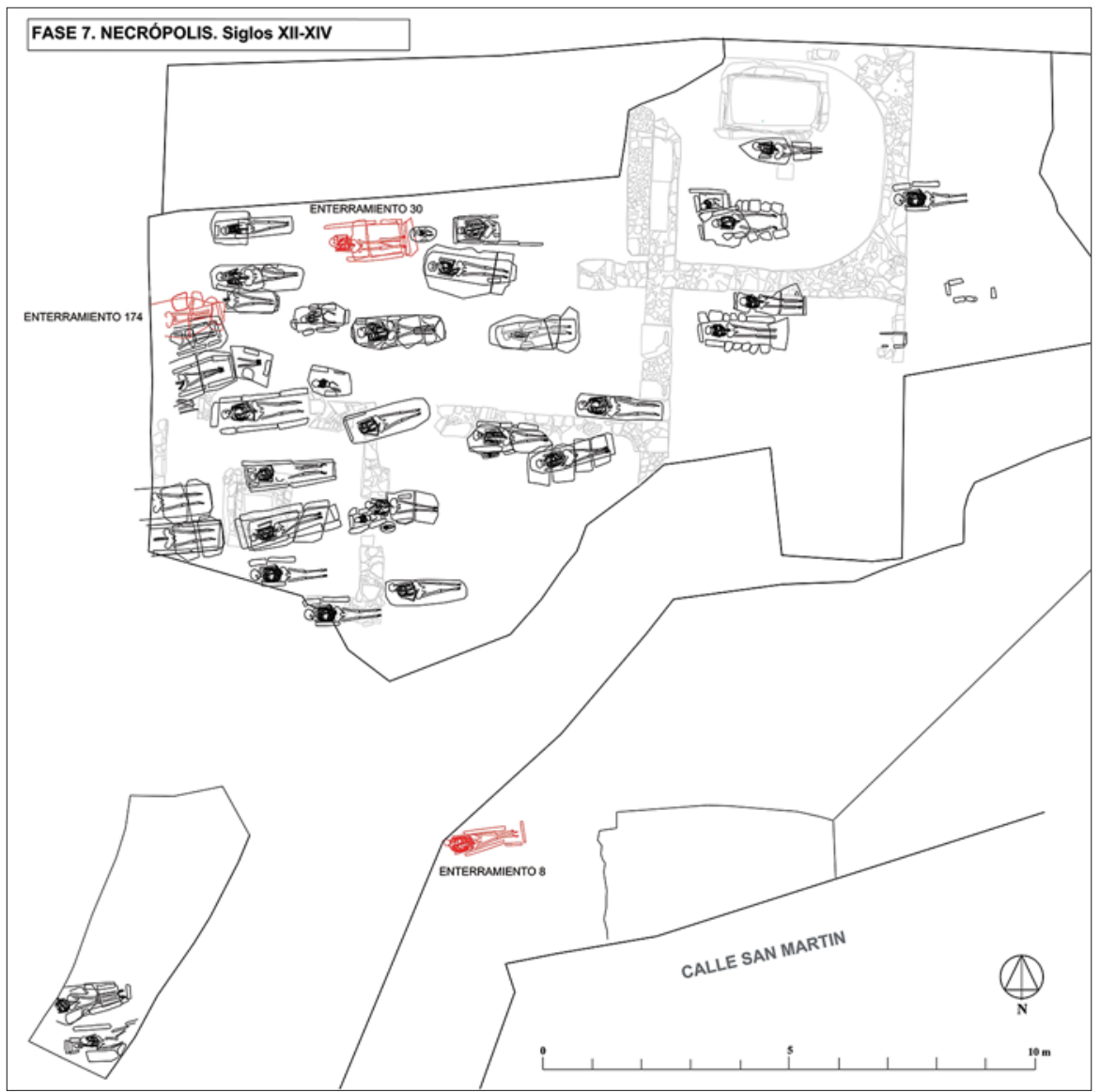

Fig. 7. Planta con los enterramientos atribuidos a la Fase 7 . En rojo las tumbas donde aparecieron las monedas. / Plant with the burials attributed to Phase 7 . In red, the tombs where the coins appeared. pacio de uso predominantemente funerario en el que destacan aquellos periodos históricos de escasa circulación monetaria, los comprendidos entre los siglos V y XII.

Quizá, la fase de ocupación romana (siglos I-IV d.C.) pudiera haber sido la excepción que confirma la regla; si bien, las fuertes alteraciones postdeposicionales sufridas en estadios ulteriores (la mayoría de piezas de época imperial aparecen estratigráficamente descontextualizadas) unido a que es muy probable que nos hallemos ante un área excéntrica dentro de la trama urbana del asentamiento, provocaron sin duda una menor cadencia de hallazgos.

La caída del Imperio romano de Occidente va a desencadenar una insuficiente renovación de la masa circulante que no comenzará a corregirse hasta bien entrada la undécima centuria. Dicha circunstancia se aprecia con meridiana claridad en San Martín de Dulantzi, siendo extensible al resto del registro arqueológico provincial, donde son extrañísimos los testimonios numismáticos de la Antigüedad Tardía y la Alta Edad Media. No es ocioso recordar al respecto como buena parte de la secuencia estratigráfica del yacimiento se desarrolla a lo largo de ese periodo, en especial, durante los siglos $\mathrm{VI}-\mathrm{IX}$.

El inicio de las acuñaciones de los reinos cristianos peninsulares en el último tercio del siglo $\mathrm{XI}$, en un primer momento en Aragón-Pamplona y posteriormente en los reinos de Castilla-León, va a poner el punto final a varias centurias de marginalidad monetaria. De hecho, estas primeras emisiones aragonesas-pamplonesas como castellano-leonesas se documentan en la fase plenomedieval de la necrópolis (enterramientos $n^{\circ} 8$ y 30 , respectivamente). A pesar de que el hallazgo de monedas en el interior de las sepulturas tiende a vincularse con pagos efectuados al barquero Caronte o con el surgimiento y desarrollo del concepto del Purgatorio, intuimos que su presencia en las tumbas medievales admite variadas lecturas a la vista de la diversa casuística reconocida (SÁNCHEZ y ROMA, 2014). Por ejemplo, en el cementerio de San Martín, ninguna de las tres monedas medievales halladas dentro de sendas sepulturas se depositó junto al difunto, aunque si fueron arrojadas en la tierra inmediatamente vertida sobre los cuerpos.

Aquellas primeras labras de las monarquías aragonesa y castellana se caracterizan por una masiva acuñación de piezas promovidas al calor de las importantes cantidades de plata obtenidas muy posiblemente a través de recientes botines de guerra (anexión del reino de Pamplona en el 1076, conquista de Toledo en 1085, de Monzón en 1089,...) y/o de las suculentas parias cobradas a los reinos de taifas (IBÁÑEZ, 2001: 91; ROMA, 2000: 28). Empero, pronto la notoria falta de plata en los mercados va a provocar un descenso continuado en el peso y la ley de los ejemplares 
emitidos (IBÁÑEZ, 2000: 65-66), así como la fabricación de piezas de cobre recubiertas por una amalgama de plata y mercurio (IBÁÑEZ, 1998: 76; SAN VICENTE, 2012: 342). El hambre de plata que caracteriza estos años traerá pareja una insuficiente renovación del numerario circulante que no comenzará a corregirse hasta bien entrada la segunda mitad de siglo XII con las emisiones de Sancho VI de Navarra (1150-1194).

En contra de lo que se pudiera esperar, la progresiva monetización de la economía del norte peninsular a partir de mediados del siglo XIII no trajo consigo un mayor número de pérdidas, o dicho con otras palabras, un mayor número de hallazgos de circulación. Antes bien, el otorgamiento del fuero de población a la villa de Alegría en 1337 provocó el inevitable abandono del lugar y en consecuencia el silencio, permítasenos la expresión, cuasi sepulcral de las fuentes arqueológicas.

Somos conscientes de la fragilidad de algunas de nuestras propuestas, sin embargo, esperamos que futuras investigaciones en el citado paraje nos ayuden a confirmar, matizar o corregir dichas afirmaciones.

\section{BIBLIOGRAFÍA}

\section{ÁLVAREZ BURGOS, F.}

1998 Catálogo general de las monedas españolas: Catálogo de la moneda medieval Castellano-Leonesa. Siglos XI al XV. Vol. III. Vico-Segarra. Madrid.

\section{AZKARATE GARAI-OLAUN, A.}

1997 Necrópolis de San Pelayo (Alegría-Dulantzi). Arkeoikuska 1996. Vitoria-Gasteiz, 165-170.

2005 Basílica de San Prudencio, en Armentia (Vitoria-Gasteiz). Arkeoikuska 2004. Vitoria-Gasteiz, 202-206.

2005-06 Sobre los orígenes cronológicos de los cementerios cispirenaicos de época tardoantigua. Munibe (Antropologia-Arkeologia) 57, Vol. 2. Homenaje a Jesús Altuna. Donostia-San Sebastián, 405-417.

2010 Catedral de Santa María (crucero y absidiolo). Arkeoikuska 2009. Vitoria-Gasteiz, 137-144.

AZKARATE GARAI-OLAUN, A.; CÁMARA MUÑOZ, L.; LASAGABASTER GÓMEZ, J. I.; LATORRE GONZÁLEZ-MORO, P.

2001 Catedral de Santa María. Vitoria-Gasteiz. Plan Director de Restauración, Vol. I-II. Diputación Foral de Álava y Fundación Catedral Santa María. Vitoria-Gasteiz.

\section{AZKARATE GARAI-OLAUN, A.; GARCÍA CAMINO, I.}

2012 El espacio circumpirenaico occidental durante los siglos $\mathrm{VI}$ al X d.C. según el registro arqueológico: algunos interrogantes. Anejos de Archivo Español de Arqueología LXIII. Madrid, 331-351.

AZKARATE GARAI-OLAUN, A.; MARTÍNEZ TORRECILLA, J. M.; SOLAUN BUSTINZA, J. L.

2011 Metalurgia y hábitat en el País Vasco de época medieval: el asentamiento ferrón de Bagoeta, Alava (ss. VII-XIV d.C.). Arqueología y territorio medieval 18. Jaén, 71-89.
AZKARATE GARAI-OLAUN, A.; SOLAUN BUSTINZA, J. L.

2009 Nacimiento y transformación de un asentamiento altomedieval en un futuro centro de poder: Gasteiz desde fines del siglo VII d.C. a inicios del segundo milenio, en QUIRÓS CASTILLO, J. A. (ed.) The archaeology of early medieval villages in Europe. Documentos de Arqueología Medieval 1. Universidad del País Vasco. Bilbao, 405-428.

\section{BARANDIARAN MAESTU, I.}

1975 Novedades sobre la Alta Edad Media en Guipúzcoa. Datos arqueológicos. Estudios de Edad Media de la Corona de Aragón, Vol. X. Zaragoza, 549-580.

\section{CALICÓ, F.; CALICÓ, X.; TRIGO, J.}

1998 Numismática española, Catálogo de todas las monedas emitidas desde los Reyes Católicos a Juan Carlos I, 1474 a 1998. $9^{a}$ edición. Xavier Calicó Estivill. Barcelona.

\section{CANTO GARCÍA, A.}

2001 La moneda hispanoárabe y su circulación por Navarra, en La moneda en Navarra. Gobierno de Navarra. Pamplona, 73-82.

\section{CANTO GARCÍA, A.; MARTÍN ESCUDERO, F; MÍNGUEZ MARTÍNEZ, J.}

2011 "La circulación monetaria en el reinado de Alfonso III a través de las fuentes documentales", en Actas I Congreso Internacional MC aniversario de la muerte de Alfonso III y la tripartición del territorio del Reino de Asturias, Vol. II. Oviedo, 157-205

\section{CEPEDA OCAMPO, J. J.}

1990 Moneda y circulación monetaria en el País Vasco durante la antigüedad (Siglos II a.C. - V d.C.). Bilbao Bizkaia Kutxa. Bilbao.

1997 La circulación monetaria romana en el País Vasco. 1er Coloquio Internacional sobre la Romanización en Euskalherria. Isturitz 8. Donostia, 259-302.

2000a Maiorina Gloria Romanorum. Monedas, tesoros y áreas de circulación en Hispania en el tránsito del siglo IV al siglo V. Archivo Español de Arqueología 73. Madrid, 161-192.

2000b A propósito de las acuñaciones del usurpador Máximo en Barcino (411). NVMISMA 244. Madrid, 43-51.

\section{CRUSAFONT i SABATER, M.}

1992 Catálogo general de las monedas españolas: Acuñaciones de la Corona Catalano-Aragonesa y de los Reinos de Aragón y Navarra. Medioevo y tránsito a la Edad Moderna. Vol. IV. Vico-Segarra. Madrid.

\section{DEPEYROT, $G$}

1998 Le numéraire mérovingien, l'âge de l'or. I, Introduction. Moneta. Wetteren

\section{DÍAZ DE DURANA ORTIZ DE URBINA, J. R.}

1986 Álava en la Baja Edad Media. Crisis, recuperación y transformaciones socioeconómicas (c. 1250-1525). Diputación Foral de Álava. Vitoria.

\section{ELMER, G.}

1941 Die Münzprägung der gallischen Kaiser in Köln, Trier und Mailand, Bonner Jahrbücher 146. Bonn, 1-106. 
FAGAN, B.

2008 La pequeña Edad de Hielo. Cómo el clima afectó a la historia de Europa (1300-1850). Gedisa. Barcelona.

\section{FERNÁNDEZ BORDEGARAI, J.; AJAMIL BAÑOS, F. J.}

2011 El yacimiento de Mavilla en Estavillo (Armiñón, Álava). Un conjunto de silos ligado a un espacio habitado entre los siglos IX-XI y su posterior amortización, en QUIRÓS CASTILLO, J. A. (ed.) Vasconia en la Alta Edad Media, 4501000. Poderes y comunidades rurales en el Norte Peninsular. Documentos de Arqueología Medieval 2. Universidad del País Vasco. Bilbao, 247-256.

\section{FILLOY NIEVA, I.; GIL ZUBILLAGA, E.}

2000 La romanización en Álava. Catálogo de la exposición permanente sobre Álava en época romana del Museo de Arqueología de Álava. Diputación Foral de Álava. Vitoria-Gasteiz.

\section{FONTECHA, R.}

1968 La moneda de vellón y cobre de la monarquía española (años 1516 a 1931). Par Artes Gráficas. Madrid.

\section{GARCÍA CAMINO, I.}

2002 Arqueología y poblamiento en Bizkaia, siglos VI-XII. La configuración de la sociedad feudal. Diputación Foral de Bizkaia. Bilbao.

\section{GARCÍA RETES, E.}

1987 El camino de San Adrián (Guipúzcoa-Álava) en la ruta jacobea. Análisis documental y arqueológico. Estudios de Arqueología Alavesa 15. Vitoria, 355-497.

\section{GAUTIER-DALCHÉ, J.}

1982 Les péages et les produits commercialisés dans les Pyrénées occidentales aux XIle et XIIle siècles, en El Fuero de San Sebastián y su época (Actas del Congreso). Eusko Ikaskuntza. San Sebastián, 235-252.

\section{GUEREÑU URCELAI, M.; URTEAGA ARTIGAS, M.}

2001 Intervención arqueológica en la iglesia de San Salvador de Getaria. Memoria. Evaluación general tipológica, interpre tación y conclusiones. Irun. (Memoria arqueológica inédita)

\section{GURRUCHAGA ANSOLA, I.}

1951 Localización de algunas ciudades várdulas citadas por Mela y Ptolomeo. Boletín del Instituto Americano de Estudios Vascos 7. Buenos Aires, 222-231.

\section{HAMEROW, $\mathrm{H}$.}

2006 'Special deposits' in Anglo-Saxon settlements. Medieval Archaeology 50. London, 1-30.

\section{IBÁÑEZ ARTICA, M}

1993-94 Catálogo Numismático de Navarra I: monetarios del Museo de Navarra y del Museo Arqueológico Nacional hasta 1305 (tipología <<románica>>: siglos XI-XIII). Trabajos de Arqueología Navarra 11. Pamplona, 141-172.

1998 Estudio metalográfico de monedas medievales: Reino de Pamplona-Navarra, siglos XI-XIII. NVMISMA 241. Madrid, 59-93.

2000 La numismática medieval navarra: antecedentes y situación actual. NVMISMA 244. Madrid, 61-113.
2001 Primeras emisiones monetarias Aragonesas-Pamplonesas, en La moneda en Navarra. Gobierno de Navarra. Pamplona, 83-96.

2007 Hallazgos monetarios en contextos funerarios (Guipúzcoa y Navarra). NVMISMA 251. Madrid, 275-293.

IBÁÑEZ ARTICA, M.; GUEREÑU URZELAI, M.; LÓPEZ COLOM, $\mathrm{M}^{\mathrm{a}}$ del $\mathrm{M}$.

1997 El hallazgo monetario de la iglesia de San Esteban (Oiartzun) 1995. Oiartzungo Udala. Oiartzun.

\section{IRIARTE KORTÁZAR, A.}

1998 La necrópolis de San Pelayo (Alegría-Dulantzi, Álava) y la cuestión de la fecha de inicio de las necrópolis de tipo merovingio en Álava. Cuadernos de Arqueología de la Universidad de Navarra 6. Pamplona, 139-163.

\section{KELLEHER, R.}

2012 The re-use of coins in medieval England and Wales C. 1050-1550: An introductory survey. Yorkshire Numismatist, Vol. 4. Yorkshire, 183-200.

LAMB, H. H.

1982 Climate, History and the Modern World. Methuen. London.

LEAHY, K

2003 Middle Anglo-Saxon Licolnshire: An Emerging Picture, en PESTELL, T. and ULMSCHNEIDER, K. (ed.) Markets in Early Medieval Europe: Trading and 'Productive' Sites, 650-850. Windgather Press. Cheshire, 138-154.

\section{LE ROY LADURIE, E.}

1971 Times of feast, times of famine: a history of climate since the year 1000. Doubleday. Garden City.

\section{LLANOS, A.; APELLÁNIZ, J. M.; AGORRETA, J. A; FARIÑA, J.}

1975 El castro del Castillo de Henayo (Alegría-Álava). Memoria de excavaciones. Campañas de 1969-1970. Estudios de Arqueología Alavesa 8. Vitoria, 87-212.

\section{MAROT SALSAS, T.}

2001 La moneda en Navarra durante la antigüedad tardía y la Alta Edad Media (Siglos V-IX), en La moneda en Navarra. Gobierno de Navarra. Pamplona, 67-72.

NEWMAN, J.

2003 Exceptional Finds, Exceptional Sites? Barham and Coddenham, Suffolk, en PESTELL, T. and ULMSCHNEIDER, K. (ed.) Markets in Early Medieval Europe: Trading and 'Productive' Sites, 650-850. Windgather Press. Cheshire, 97-109.

\section{NISO LORENZO, J.; LOZA URIARTE, M.}

2012 Yacimiento de San Martín de Dulantzi. Arkeoikuska 2011. Vitoria-Gasteiz, 35-57.

\section{NÚÑEZ MARCÉN, J.}

2003 La calzada 'Astorga-Burdeos' (ab Asturica Burdigalam): elemento de articulación del territorio y de romanización, en PASTOR DÍAZ DE GARAYO, E. (ed.) La Llanada Oriental a través de la historia: claves desde el presente para comprender nuestro pasado. Diputación Foral de Alava. Vitoria-Gasteiz, 35-41. 
OCHARAN LARRONDO, J. A.

1983 Hallazgo de un tremis visigodo en la Peña de Orduña (Vizcaya). KOBIE 13. Bilbao, 85-93.

2009 La circulación de moneda en Álava hacia el año 1.000 KOBIE (Serie paleoantropología) 28. Bilbao, 247-254.

PÉREZ SOLER, M ${ }^{\mathrm{a}} \mathrm{D}$.

1970 Cartulario de Valpuesta. Anubar. Valencia.

PESTELL, T.

2003 The Afterlife of 'Productive' Sites in East Anglia, en PESTELL, T. and ULMSCHNEIDER, K. (ed.) Markets in Early Medieval Europe: Trading and 'Productive' Sites, 650-850 Windgather Press. Cheshire, 122-137.

POZO FLORES, M.

2011 La barbarie como explicación histórica y sus problemas: los vascones de los siglos VI y VII. Miscelánea Medieval Murciana XXXV. Murcia, 189-200

\section{QUIRÓS CASTILLO, J. A.}

2009 Arqueología del campesinado altomedieval: las aldeas y las granjas del País Vasco, en QUIRÓS CASTILLO, J. A (ed.) The archaeology of early medieval villages in Europe. Documentos de Arqueología Medieval 1. Universidad del País Vasco. Bilbao, 385-403.

(ed.) 2011 Vasconia en la Alta Edad Media, 450-1000. Poderes y comunidades rurales en el Norte Peninsular. Documentos de Arqueología Medieval 2. Universidad del País Vasco. Bilbao.

QUIRÓS CASTILLO, J. A.; LOZA URIARTE, M.; NISO LORENZO, J.

2013 Identidades y ajuares en las necrópolis altomedievales. Estudios isotópicos del cementerio de San Martín de Dulantzi, Alava (siglos VI-X). Archivo Español de Arqueología 86. Madrid, 215-232.

\section{RETAMERO SERRALVO, F.}

2011 La moneda del Regnum Gothorum (ça. 575-714). Una revisión del registro numismático, en DÍAZ MARTíNEZ, P. C \& MARTÍN VISO, I. (ed.) BETWEEN TAXATION AND RENT. Fiscal problems from Late Antiquity to Early Middle Ages. ENTRE EL IMPUESTO Y LA RENTA. Problemas de la fiscalidad tardoantigua y altomedieval. Edipuglia. Bari, 189-220.

ROMA VALDÉS, A.

2000 Moneda y sistemas monetarios en Castilla y en León durante la Edad Media (1087-1366). Asociación Numismática Española. Barcelona.

2010 Emisiones monetarias leonesas y castellanas de la Edad Media. Organización, economía, tipos y fuentes. Morabetino.es. A Coruña.

SÁENZ DE URTURI RODRÍGUEZ, P.; NÚÑEZ MARCÉN, J.

2004 Yacimiento de Mariturri (Vitoria-Gasteiz). Arkeoikuska 2003. Vitoria-Gasteiz, 194-202.

\section{SÁNCHEZ RINCÓN, R.}

2008 Nuevas variantes de monedas de Alfonso VIII (11581214) en territorios recién conquistados. Gaceta Numismática 170-171. Barcelona, 7-16.
2011 La evolución del hábitat en el yacimiento de San Andrés (Salinas de Añana, Álava). Primeras aproximaciones. Estudios de Arqueología Alavesa 27. Vitoria-Gasteiz, 217-228.

\section{SÁNCHEZ RINCÓN, R.; ROMA VALDÉS, A.}

2014 La otra cara de la moneda. Uso y reutilización de la moneda en la Edad Media del Noroeste Peninsular (II). NVMISMA 258. Madrid. (En prensa)

\section{SAN VICENTE GONZÁLEZ DE ASPURU, J. I.}

2012 Trueque, circulación monetaria, y atesoramiento en el despoblado de Zaballa (Álava), en QUIRÓS CASTILLO , J. A. (ed.) Arqueología del campesinado medieval: la aldea de Zaballa. Documentos de Arqueología Medieval 3. Universidad del País Vasco. Bilbao, 339-360.

2013 Trueque, unidades de cuenta y circulación monetaria en la etapa prefundacional de Vitoria-Gasteiz, en Arqueología e Historia de una ciudad. Los orígenes de Vitoria-Gasteiz. Tomo I. Universidad del País Vasco. Bilbao, 357-379.

\section{UBIETO ARTETA, A.}

1976 Cartulario de San Millán de la Cogolla (759-1076). Anubar. Valencia.

\section{ULMSCHNEIDER, K.; PESTELL, T.}

2003 Introduction: Early Medieval Markets and 'Productive' Sites, en PESTELL, T. and ULMSCHNEIDER, K. (ed.) Markets in Early Medieval Europe: Trading and 'Productive' Sites, 650-850. Windgather Press. Cheshire, 1-10.

\section{VAQUERIZO GIL, D.}

2002 Espacio y usos funerarios en Corduba. Espacios y usos funerarios en el Occidente romano: Actas del Congreso Internacional, Vol. 2. Córdoba, 141-200.

WEBB, P. H.

1968 The Roman Imperial Coinage V. Part. II. Spink. London.

\section{5.- CATÁLOGO}
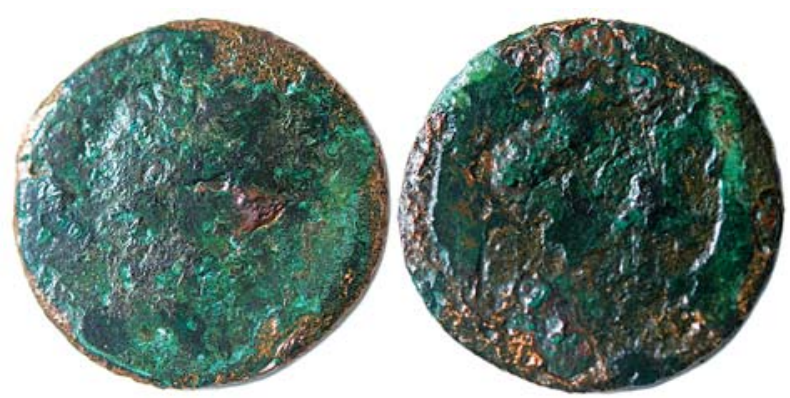

(1) As, época altoimperial, siglos I-II d.C.

Anverso: llegible. ¿Busto? del emperador, a la derecha.

Reverso: Frustro.

No Inventario: SMAA.10.35.252

Metrología:

Peso: 8,06 gr. Módulo: $25 \mathrm{~mm}$.

Dirección de cuños: ¿?

Referencia Bibliográfica:

RIC? 

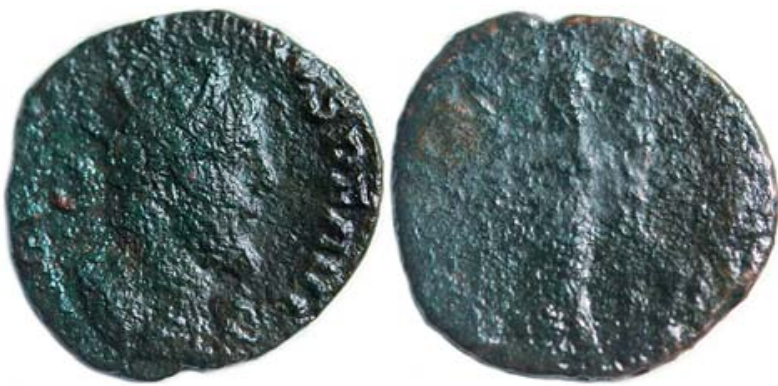

(2) Antoniniano, Victorino, Tréveris, 268-270 d.C.

Anverso: IMP [ C ... victorin]VS P F AVG. Busto radiado del emperador con ¿paludamentum? y coraza, a la derecha. Reverso: [fides militvm]. Fides, estante, a la izquierda, sosteniendo un estandarte en cada mano.

N Inventario: SMAA.10.3090.4

\section{Metrología:}

Peso: 2,09 gr. Módulo: $19 \mathrm{~mm}$.

Dirección de cuños: $6 \mathrm{H}$

\section{Referencia Bibliográfica:}

\section{ELMER, G.}

1941 "Die Münzprägung der gallischen Kaiser in Köln, Trier und Mailand", Bonner Jahrbücher 146,Bonn, pp. 65-68, n 648, 654, 677 ó 684

WEBB, P. H.

1968 The Roman Imperial Coinage V, Part. II, London, p. 396, n 108, 109 ó 110.
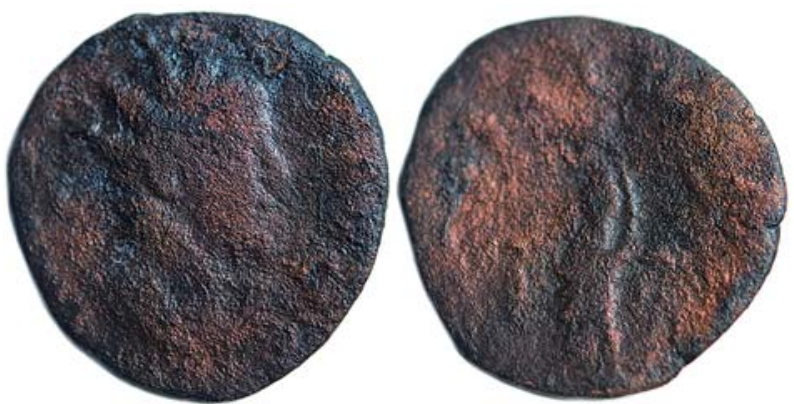

(3) Antoniniano, ¿Tétrico I, Tréveris, 273 d.C.?

Anverso: llegible. Busto radiado del emperador con ¿coraza?, a la derecha.

Reverso: Ilegible. ¿Hilaritas, estante, a la izquierda, portando palma y cornucopia?

NN Inventario: SMAA.10.1.198

\section{Metrología:}

Peso: 1,44 gr. Módulo: $17 \mathrm{~mm}$.

Dirección de cuños: $7 \mathrm{H}$

\section{Referencia Bibliográfica:}

ELMER, G.

1941 "Die Münzprägung der gallischen Kaiser in Köln, Trier und Mailand", Bonner Jahrbücher 146, Bonn, p. 84, ¿n 789 ó $790 ?$

WEBB, P. H.

1968 The Roman Imperial Coinage V, Part. II, London, p. 408, ¿nº 79, 80 ó 81 ?
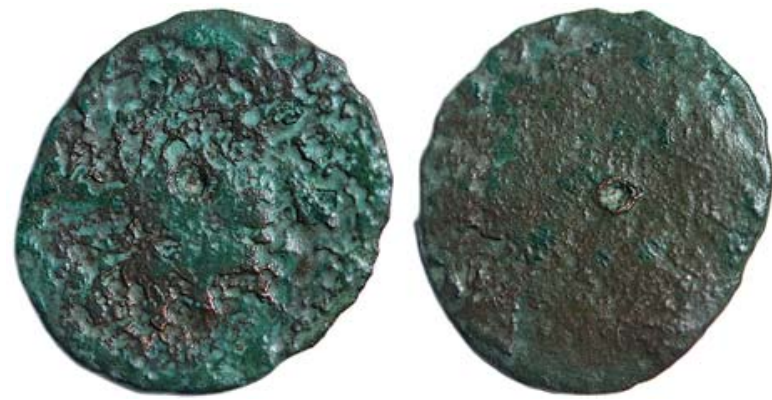

(4) ¿Aes 3, Siglo IV d.C.?

Anverso: Irreconocible.

Reverso: Irreconocible.

No Inventario: SMAA. 10.74.114

Metrología:

Peso: $1,34 \mathrm{gr}$. Módulo: $18 \mathrm{~mm}$.

Dirección de cuños: ¿?

Referencia Bibliográfica:

$\mathrm{RIC}$ ?

\section{Observaciones:}

Presenta en ambas caras sendos orificios pareados, más o menos en el centro de la moneda, que no llegan a atravesarla en todo su espesor.
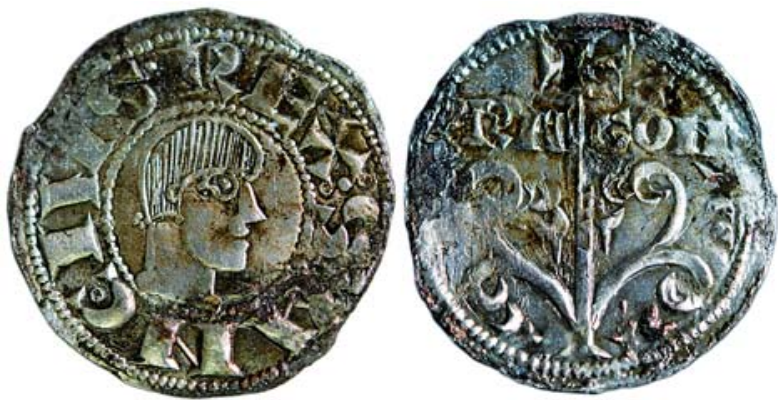

(5) Dinero jaqués, Sancho V Ramírez de Aragón y Pamplona (1063-1094), ¿Jaca?, ca. 1076-1094.

Anverso: SANCIVS REX. Busto desnudo a la derecha, en gráfila circular de puntos. Ojo lacrimal marcado, pelo resuelto en líneas verticales y tocado en la nuca consistente en tres bolitas. Letra E recta. Tres puntos, seguidos y dispuestos verticalmente, al inicio de la leyenda; aro dentro de la letra $\mathrm{C}$ y punto entre las letras $\mathrm{S}$ y $\mathrm{R}$.

Reverso: ARA-GON. "Árbol crucífero" sencillo con las ramas laterales surgiendo por encima de la base, ocupando el campo dentro de gráfila circular de puntos, con estrella de ¿cinco puntas? maciza a la derecha de la cruz. Letras A y $R$ nexadas y repintadas (sobreacuñadas). No Inventario: SMAA.10.1080.17

\section{Metrología:}

Peso: 0,98 gr. Módulo: $19 \mathrm{~mm}$.

Dirección de cuños: $12 \mathrm{H}$ 
Referencia Bibliográfica:

CRUSAFONT i SABATER, M.

1992 Catálogo general de las monedas españolas: Acuñaciones de la Corona Catalano-Aragonesa y de los Reinos de Aragón y Navarra. Medioevo y tránsito a la Edad Moderna, Vol. IV, Madrid, p. 50, $n^{\circ}$ 198.1. Similar, variante no recogida.

IBÁÑEZ ARTICA, M.

1993-94 "Catálogo Numismático de Navarra I: monetarios del Museo de Navarra y del Museo Arqueológico Nacional hasta 1305 (tipología <<románica>> : siglos XI-XIII)", Trabajos de Arqueología Navarra 11, Pamplona, p. 156, tipo S-II.B.2.

2001 "Primeras emisiones monetarias Aragonesas-Pamplonesas", La moneda en Navarra, Pamplona, p. 93, tipo S-II.B.2.b.

\section{Observaciones:}

Tanto en el anverso como en el reverso de la pieza se aprecian pequeñas manchas y/o concreciones de color rojizo.
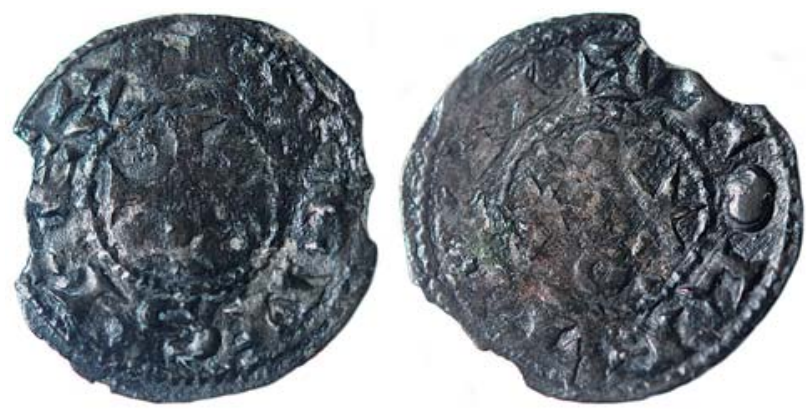

(6) Meaja, Alfonso VI de Castilla y León (1073-1109), ca. 1087-1090.

Anverso: ANFVS REX. Cruz patada en gráfila circular de puntos.

Reverso: + TOLETVM. Dos aros y dos estrellas de seis puntas macizas en gráfila circular de puntos.

No Inventario: SMAA. 10.1300.11

\section{Metrología:}

Peso: 0,20 gr. Módulo: $15 \mathrm{~mm}$.

Dirección de cuños: $1 \mathrm{H}$

Referencia Bibliográfica:

ÁLVAREZ BURGOS, F.

1998 Catálogo general de las monedas españolas: Catálogo de la moneda medieval Castellano-Leonesa. Siglos XI al XV, Vol. III, Madrid, p. 15, nº.

ROMA VALDÉS, A.

2000 Moneda y sistemas monetarios en Castilla y en León durante la Edad Media (1087-1366), Barcelona, p. 26, n 1 'a.

2010 Emisiones monetarias leonesas y castellanas de la Edad Media. Organización, economía, tipos y fuentes, p. $157, n^{\circ} 2.1$.
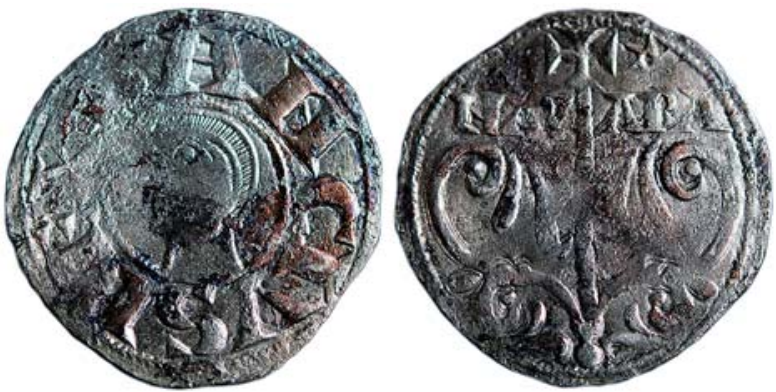

(7) Dinero, Sancho VI de Navarra (1150-1194).

Anverso: SANCIVS REX. Busto desnudo a la izquierda, en gráfila circular de puntos. Ojo lacrimal marcado y pelo resuelto en líneas rectas subverticales. Tres puntos, seguidos y dispuestos verticalmente, al inicio de la leyenda.

Reverso: NAV-ARA, en horizontal. "Árbol crucífero" sencillo con las ramas laterales saliendo por encima de la base del vástago central, ocupando el campo dentro de gráfila circular de puntos, con estrellas de seis puntas de umbo central a ambos lados de la cruz.

NN Inventario: SMAA.10.2740.2

Metrología:

Peso: 0,90 gr. Módulo: $18 \mathrm{~mm}$.

Dirección de cuños: $9 \mathrm{H}$

\section{Referencia Bibliográfica:}

CRUSAFONT i SABATER, M.

1992 Catálogo general de las monedas españolas: Acuñaciones de la Corona Catalano-Aragonesa y de los Reinos de Aragón y Navarra. Medioevo y tránsito a la Edad Moderna, Vol. IV, Madrid, p. 48, $n^{\circ} 193$.

IBÁÑEZ ARTICA, M.

1993-94 "Catálogo Numismático de Navarra I: monetarios del Museo de Navarra y del Museo Arqueológico Nacional hasta 1305 (tipología <<románica>> : siglos XI-XIII)", Trabajos de Arqueología Navarra 11, Pamplona, p. 157, tipo S-VI.b.

\section{Observaciones:}

Al igual que ocurre con el dinero jaqués de Sancho V Ramírez ( $n^{\circ} 5$ ), aunque en mayor medida, el numisma presenta amplias zonas de color rojizo.
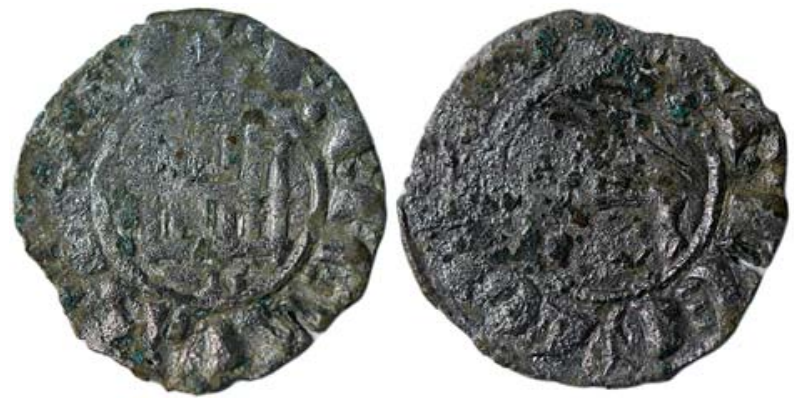
(8) Dinero, Fernando IV de Castilla y León (1295-1312), Burgos, 1297.

Anverso: + :F: REGIS CAST[el]LE. Castillo con tres torres en gráfila circular. Bajo el castillo, marca de ceca, letra B. Reverso: + ET LEGIO[n]I[s]. León a la izquierda en gráfila circular.

No Inventario: SMAA.10.11.79

\section{Metrología:}

Peso: 0,44 gr. Módulo: $18 \mathrm{~mm}$.

Dirección de cuños: $5 \mathrm{H}$

Referencia Bibliográfica:

ÁLVAREZ BURGOS, F.

1998 Catálogo general de las monedas españolas: Catálogo de la moneda medieval Castellano-Leonesa. Siglos XI al XV, Vol. III, Madrid, p. 78, n 319.1.

ROMA VALDÉS, A.

2000 Moneda y sistemas monetarios en Castilla y en León durante la Edad Media (1087-1366), BarceIona, p. 230, Grupo A.

2010 Emisiones monetarias leonesas y castellanas de la Edad Media. Organización, economía, tipos y fuentes, p. 221, n²16.1-a
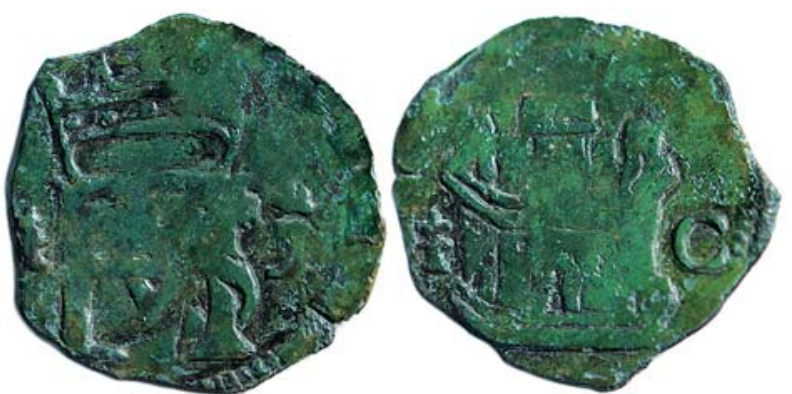

(9) Blanca, Felipe II (1556-1598), Cuenca, 1568-1576. Anverso: PHVS. Monograma de PHILIPPVS coronado en gráfila circular de puntos. A la izquierda, cruz patriarcal, sigla del ensayador Pedro Román; a la derecha, marca de ceca cáliz coronado por una estrella de seis puntas.

Reverso: Castillo de tres torres, ocupando el campo, en gráfila circular de puntos. A la izquierda, cruz patriarcal, a la derecha, letra $\mathrm{C}$.

No Inventario: SMAA.10.1.197

\section{Metrología:}

Peso: 0,58 gr. Módulo: $16 \mathrm{~mm}$.

Dirección de cuños: $10 \mathrm{H}$

\section{Referencia Bibliográfica:}

CALICÓ, F., X. \& TRIGO, J.

1998 Numismática española, Catálogo de todas las monedas emitidas desde los Reyes Católicos a Juan Carlos I, 1474 a 1998, 9 a edición, Barcelona, p. 195, tipo 362, n 722 . Similar, variante no recogida. FONTECHA, R.

1968 La moneda de vellón y cobre de la monarquía española (años 1516 a 1931), Madrid, p. 39, n 52.
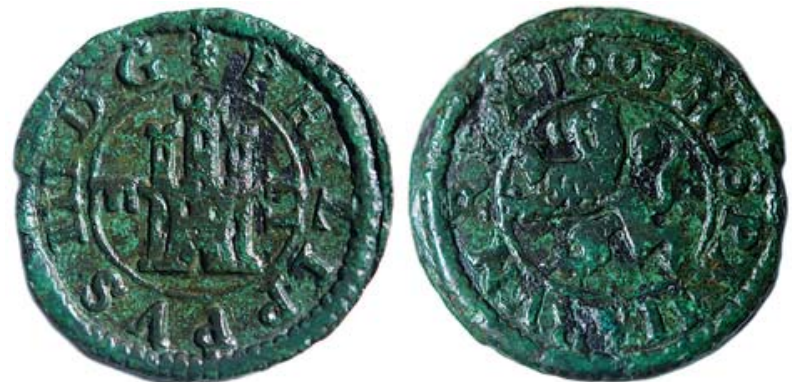

(10) Dos maravedís, Felipe III (1598-1621), ingenio de Segovia, 1603

Anverso: + PHILIPPVS III DG. Castillo de tres torres dentro de gráfila circular. A la izquierda, marca de ceca, acueducto de Segovia en posición horizontal, a la derecha, indicación de valor, II.

Reverso: HISPANIARVM REX 1603. León coronado rampante dentro de gráfila circular.

No Inventario: SMAA.10.1.199

\section{Metrología:}

Peso: 1,19 gr. Módulo: $17 \mathrm{~mm}$.

Dirección de cuños: $12 \mathrm{H}$

\section{Referencia Bibliográfica:}

CALICÓ, F., X. \& TRIGO, J.

1998 Numismática española, Catálogo de todas las monedas emitidas desde los Reyes Católicos a Juan Carlos I, 1474 a 1998, 9 a edición, Barcelona, p. 237, tipo 159, n 686 .

FONTECHA, R.

1968 La moneda de vellón y cobre de la monarquía española (años 1516 a 1931), Madrid, p. 55, n 145. 
